\title{
El enfrentamiento de Mayans y los Iriarte a propósito de las gramáticas latinas
}

\author{
Miguel A. Perdomo-Batista \\ Universidad de Las Palmas de Gran Canaria \\ mperdomo@dfe.ulpgc.es
}

Recibido: 18 de julio de 2011

Aceptado: 21 de noviembre de 2011

\section{RESUMEN}

En la historiografía tradicional, y a propósito del pleito de las gramáticas latinas, generalmente se ha presentado a Mayans como una víctima inerme de las intrigas de los Iriarte, y esta imagen coincide con la que don Gregorio a menudo presentó de sí mismo. Sin embargo, un análisis de este enfrentamiento en relación con las otras polémicas en las que resultó implicado el valenciano pone de manifiesto que los hechos deben ser interpretados en un contexto más amplio y más complejo que trasciende los enfrentamientos y las meras ambiciones personales, y que también caracteriza a la sociedad y la cultura españolas del siglo XVIII: el reformismo borbónico, la renovación de las enseñanzas del latín, el clientelismo político y la lucha de facciones y las nuevas formas de socialización de los literatos. Esta interpretación sugiere la necesidad de una historiografía de la lingüística de carácter hermenéutico.

Palabras clave: Iriarte. Mayans. Gramática latina. Ilustración española.

Perdomo-Batista, M. A., «El enfrentamiento de Mayans y los Iriarte a propósito de las gramáticas latinas», Cuad. Fil. Clás. Estud. Lat. 31.2 (2011) 355-388.

\section{The confrontation between Mayans and the Iriarte with respect to the Latin grammars}

\begin{abstract}
In traditional historiography, and with regard to the litigation of the Latin grammars, usually presented to Mayans as defenseless victims of the machinations of the Iriarte, and this picture agrees with that Don Gregorio often presented itself. However, an analysis of this conflict in relation to the other controversies in which it was implied the valencian shows that the facts must be interpreted in a broader context and more complex that transcends mere confrontations and personal ambitions, and that also characterizes the Spanish society and culture of the eighteenth century: the Bourbon reforms, the renewal of the teaching of Latin, the political patronage and factional fighting and the new forms of socialization of the writers.
\end{abstract}

Keywords: Iriarte. Mayans. Latin grammar. Hispanic Enlightenment.

Perdomo-Batista, M. A., «The confrontation between Mayans and the Iriarte with respect to the Latin grammars», Cuad. Fil. Clás. Estud. Lat. 31.2 (2011) 355-388.

SuMARIo 1. Introducción. 2. Los primeros enfrentamientos: de la cátedra de Valencia a la Real Biblioteca (1727-1739). 2.1. La polémica por la Ortografía de Bordazar. 2.2. Las desavenencias en la Real Biblioteca. 2.3. El enfrentamiento con el Diario de los Literatos de España y las Reales Academias. 3. El retiro en Oliva y los últimos años en Valencia (1739-1781). 3.1. Las suspicacias por las anotaciones 
a la Bibliotheca de Casiri. 3.2. La polémica del catálogo de los manuscritos griegos y el pleito de las gramáticas latinas. 3.3. La continuación de la polémica tras la muerte de don Juan de Iriarte en 1771: Los literatos en cuaresma. 3.4. La intervención de los Iriarte. 3.5. La pugna por las gramáticas latinas en Valencia. 4. Las razones del enfrentamiento y de sus consecuencias. 5. Conclusiones para la historiografía de la gramática latina del siglo XVIII en España. 6. Referencias bibliográficas.

\section{INTRODUCCIÓN}

En el pleito de las gramáticas latinas, la historiografía generalmente ha presentado a Mayans como una víctima inerme de las maquinaciones de los Iriarte, y esta imagen coincide con la que don Gregorio a menudo presentó de sí mismo y con el testimonio que ofrece la correspondencia que conservamos, particularmente la del bibliotecario Manuel Martínez Pingarrón, su confidente en la Real Biblioteca.

Según Antonio Mestre (Mayans y Siscar, 1989; Mestre Sanchis, 1999), la historia del enfrentamiento por las gramáticas latinas puede explicarse del siguiente modo. Juan de Iriarte, que venía preparando una gramática desde hacía cuarenta años, fue presionado por sus sobrinos, que estaban empleados en la secretaría de Estado, para que la terminara. A través del Duque de Béjar, los Iriarte buscaron para su gramática la protección de los Infantes, a quienes iba dedicada la obra y a cuya costa se imprimiría con la aprobación del duque. Como don Juan estaba muy enfermo, se busco la ayuda de José Rodríguez de Castro, escribiente de la Biblioteca, que puso reparos y exigió la orden expresa del rey. No obstante, con la ayuda de Santander pronto se consiguió la colaboración de Cerdá y Rico, que deseaba entrar en la Biblioteca y editar las obras de Matamoros.

Así pues, se habían allanado los obstáculos para que la Gramática de Iriarte viera la luz, aunque todavía existía un serio impedimento. En efecto, don Juan había expuesto en su Biblioteca griega los errores de Pérez Bayer en la atribución de la primera traducción castellana de la Odisea. Pérez Bayer había sido nombrado preceptor de los hijos de Carlos III tras la expulsión de los jesuitas, y debía autorizar la dedicatoria de la Gramática de Iriarte a los Infantes. Debe advertirse que el empleo de Pérez Bayer trascendía la enseñanza de los niños de la familia real, pues dada la superior posición de estos su preceptor se convertía en una suerte de director de estudios. Pérez Bayer estaba muy interesado en publicar una traducción de Salustio hecha por el infante don Gabriel con su ayuda, porque demostraría las bondades de su magisterio. Como la edición de Salustio requería la aprobación del Duque de Béjar, que era el ayo de los Infantes, el arreglo fue el siguiente. Iriarte, presionado por sus sobrinos, suprimió las críticas a Pérez Bayer de la Biblioteca griega, que ya estaba impresa pero no publicada, y dio su Gramática a la corrección de Pérez Bayer, que autorizó la dedicatoria a los Infantes y la publicación. Por su parte, el Duque de Béjar permitió la lujosa edición del Salustio, que llevaba notas y apéndices del mismo Bayer. Así pues, y según afirma Antonio Mestre, la Gramática de Iriarte nacía con todos los favores: «dedicatoria a los Infantes reales que pagaron la edición, beneplácito del preceptor Pérez Bayer, satisfacción del ayo de los Infantes y mecenas de los Iriarte, alegría de los sobrinos que lograron, además, el acceso del pequeño de los Iriarte, Tomás, el conocido fabulista, a la secretaría de Estado». 
Hasta aquí el relato de Mestre, que se atiene a la lógica de los hechos según la interpretación de Mayans y Pingarrón. Y en efecto, tras la lectura de la correspondencia que ambos nos dejaron se tiene la sensación de que don Gregorio fue una víctima inocente de las intrigas de los Iriarte. Y ciertamente don Gregorio bien pudo ser una víctima de los Iriarte, pero desde luego no fue una víctima indefensa; Mayans se defendió con todos los medios a su alcance, y no solo lo hizo bien, sino que a veces hizo algo más que eso, como veremos después. Pero lo más importante es que en el enfrentamiento entre Mayans y los Iriarte se concitan otras importantes circunstancias que explican el origen, la naturaleza y el alcance del conflicto, de modo que los hechos deben ser interpretados en un contexto más amplio y complejo que trascienda las disputas ocasionadas por las meras ambiciones personales. Para examinar el influjo de aquellas circunstancias nos proponemos estudiar el pleito de las gramáticas latinas en relación con las otras polémicas en las que también resultó implicado don Gregorio, y en particular sus enfrentamientos con los Iriarte. A ello dedicaremos las siguientes páginas.

\section{LOS PRIMEROS ENFRENTAMIENTOS: DE LA CÁTEDRA DE VALENCIA A LA REAL BIBLIOTECA (1727-1739)}

\subsection{LA POLÉMICA POR LA ORTOGRAFÍA DE BORDAZAR}

La primera de estas disputas tuvo lugar a raíz de la edición de la Ortografía española de Antonio Bordazar en 1728. Según cuenta Antonio Mestre (1978, pp.123-128), tras escuchar una disertación de Mayans sobre la ortografía castellana, el editor valenciano Antonio Bordazar publicó con su nombre una Ortografia española que muchos atribuyeron a don Gregorio dadas las semejanzas entre sus propias ideas y las expuestas por Bordazar. Aunque mantenía ciertas diferencias respecto de las ideas de Bordazar, Mayans alabó la obra, y pidió a su autor que enviase un ejemplar a Feijoo, que la celebró con entusiasmo en una carta que Bordazar publicó enseguida. Empero, muchos pensaban que el verdadero autor de la obra era don Gregorio. Tal es el caso de José Pardo de Figueroa, buen amigo de Mayans, Feijoo e Iriarte, que vivía en su casa. También debía compartir esta opinión Feijoo, porque cuando Pardo de Figueroa le pidió su parecer sobre la Ortografia, el benedictino afirmó que el autor de la obra era Mayans, según le constaba por unos comentarios del propio valenciano, y añadió unas palabras de desdén sobre las obras de don Gregorio. Todo esto hubiera permanecido oculto si Iriarte no hubiera entregado la carta de Feijoo a José Mañer tras cogerla de la escribanía de Pardo de Figueroa durante una ausencia de este. Naturalmente, Mañer hizo público el contenido de la carta. Mayans escribió una amenazadora carta latina a Feijoo pidiéndole que se retractara, y como así lo hiciera el Padre Maestro en otra carta, en 1731 don Gregorio la publicó acompañada de una suya en la que elogiaba al benedictino y le expresaba su afecto ${ }^{1}$. Todo parecía resuelto, pero a partir de entonces las relaciones en-

${ }^{1}$ Carta del Rmo. P. M. Fr. Benito Jerónimo Feijoo, Maestro General de la Religión de San Benito [...] escrita a don Gregorio Mayans y Siscar [...] cuya respuesta la adjunta. [S. 1. ], [s. n. ], [s. a. ]. La última carta de 
tre Feijoo y Mayans no serían fáciles, y aunque ambos supieron guardar la compostura públicamente, ninguno renunció a mostrar sus discrepancias, unas veces de forma velada y otras explícitamente. En cualquier caso, lo que ahora nos interesa es la participación de Iriarte en este asunto: ¿qué razones pudo tener don Juan para sustraer la carta de Feijoo de la escribanía de Pardo de Figueroa y entregársela a Mañer?

Según Mestre Sanchis (1999), Iriarte había entregado unos versos latinos a Pardo de Figueroa, que sin conocimiento de su autor los envió a Mayans para que este le diera su parecer, que no fue muy favorable. Cuando Iriarte lo conoció, cogió la carta en la que Feijoo exponía a Pardo de Figueroa su opinión sobre la autoría de la Ortografía de Bordazar y se la dio a Mañer, que al poco la hizo pública. Así lo cuenta Mayans al P. Burriel en carta del 6 de agosto de 1746 (Mayans y Siscar 1972, pp.290-291).

Cabe suponer que Mañer aprovechó la indiscreción de Iriarte para atacar a Feijoo, a quien veía como la personificación de las ideas reformistas. De otro modo no se comprende la actitud de Iriarte ni su papel en este conflicto, pues es notorio que don Juan formaba parte de la tertulia de Sarmiento y, por tanto, estaba próximo a las ideas de Feijoo. Sabemos además que José Mañer tuvo después diferencias con Sarmiento y Feijoo, y que estas se remontaban a la época en que malévolamente quiso hacer pública la carta. En cambio, no hallamos ambigüedad en la conducta de Iriarte, que en 1737 salió en defensa de los benedictinos ${ }^{2}$, y más tarde publicó una dura crítica contra una traducción de Mañer ${ }^{3}$ en el Diario de los Literatos de España.

Por lo demás, no se entiende que el precavido Feijoo afirmara que Mayans le había confesado ser el autor de la Ortografia, y no tanto porque así lo creyera, sino porque lo afirmaba de boca del propio don Gregorio, lo cual solo puede explicarse si consideramos que la insistencia de Mayans en revelar su magisterio intelectual sobre Bordazar pudo confundir al benedictino, que habría entendido mal las alusiones del valenciano. Las propias afirmaciones de don Gregorio en los Acta Eruditorum de Leipzig podrían confirmar esta tesis, y nos permiten pensar en un error de Feijoo, y no en un descuido o en una travesura ${ }^{4}$.

Mayans está fechada en Valencia el 7 de noviembre de 1731. Mayans relató al Conde de Ericeira lo sucedido en una carta que puede consultarse en Mestre Sanchis (1978, pp.153-156).

${ }^{2}$ Ignacio de Armesto y Ossorio se había ocupado de las polémicas entre Mañer, Sarmiento y Feijoo en su Teatro anti-crítico universal sobre las obras del muy R. P. maestro Feijoo, del P. M. Sarmiento y de don Salvador José Mañer, publicado en Madrid en 1737. Juan de Iriarte (1774, II, pp.444-449) hizo la crítica de esta obra en un artículo del Diario de los Literatos en el que Armesto no sale muy bien parado.

${ }^{3}$ Se trata del Mercurio Histórico y Político, traducido por Mañer bajo el seudónimo de Le-Margne. La crítica de don Juan puede verse en Iriarte y Cisneros (1774, II, pp.404-423).

${ }^{4}$ Según el extracto reproducido en el Diario de los Literatos de España (1737, t. III, art. VIII, pp.256-257), el texto completo publicado por don Gregorio en el Acta Eruditorum es el siguiente:

Ortografia española fijamente ajustada a la naturaleza invariable de cada una de las letras. La escribía Antonio Bordazar de Artazú. Segunda impresión, en que se añade una Apología contra las instancias vulgares, recogidas por D. Salvador Josef Mañer. En Valencia, en la imprenta del autor, A. 1730. Huius Orthographiae uerus Autor est, ipse Antonius Bordazarius, Typographus iudiciosus, \& homo summae industriae. Sunt, qui falso putant, Greg. Maiansium scripsisse illam, propterea quod ipse Autor (qua praeditus est modestia) dicere solet, fere integrum Orthographiae suae Systema a Maiansio didicisse: idque uerum est. Quanquam in usu duarum, aut trium literarum Maiansio noluit assentiri; quod si non fecisset, fortasse ab imperitis hominibus non ita conuitiis, ut nunc, impetitus fuisset. 
Respecto a don Juan de Iriarte, tampoco parece muy claro el asunto de los versos latinos que Pardo de Figueroa envió a Mayans para que este le diese su opinión, que al parecer no fue muy favorable. Según Antonio Mestre, el juicio de don Gregorio debió irritar a Iriarte, que cogió la carta de Feijoo de la escribanía de Pardo y se la dio a leer a Mañer. Mayans se refiere a este suceso en una carta a Roque Deville (Mayans y Siscar1993, pp.297-298), pero el relato de don Gregorio no refiere incidente alguno (que bien pudo ser prudentemente ocultado por el valenciano), y al parecer fue el propio Iriarte el que le envió sus versos a Mayans, al contrario de lo afirmado por Mestre, que cuenta que Pardo los envió a don Gregorio sin el conocimiento de Iriarte: «Con D. Juan [de] Iriarte no tengo comunicación. Pero sé sus prendas, y le debí la fineza que, por medio de un amigo suyo y mío [Pardo de Figueroa], sujetase una poesía suya a mi censura. Ahora no me ha escrito. Quizá por no ofrecerse argumento que le obligue a eso». Si los versos fueron enviados a Mayans por Iriarte, resultaría extraño que don Gregorio quisiera desairar su cortesía con un juicio severo; si fueron enviados sin el consentimiento de don Juan, como señala Mestre, aún resulta más extraña la imprudencia de don Gregorio. Y si en efecto la crítica de Mayans fue desfavorable, resulta igualmente raro que algunos años después don Juan volviera a enviarle sus versos, o que el mismo Mayans ofreciera a Iriarte la censura de las cartas latinas de Martí, aunque esto último también haya que entenderlo como un gesto de aproximación de don Gregorio a la Real Biblioteca en el contexto del reformismo carolino. En cualquier caso, y finalmente, tal vez podamos afirmar que el incidente de la Ortografía de Bordazar se debió a la displicencia o la ambigüedad de Mayans, la imprudencia de Feijoo, la indiscreción de Iriarte, los enredos de Pardo de Figueroa, que era amigo de los tres, y la malicia de Mañer.

\subsection{LAS DESAVENENCIAS EN LA REAL BIBLIOTECA}

Es preciso que nos ocupemos ahora de las relaciones de Mayans con los empleados de la Real Biblioteca. Don Gregorio recibió el nombramiento de bibliotecario en 1733, y ese mismo año se trasladó a Madrid. Y aunque cabe suponer que aún no se habían apagado los rescoldos de los primeros enfrentamientos entre Feijoo y Mayans y sus diferencias con Iriarte en 1731, al menos en apariencia las relaciones entre los bibliotecarios eran cordiales. Pero, según Antonio Mestre (1987), la animosidad subió nuevamente de punto cuando estos advirtieron que Mayans quería conseguir la plaza de cronista de Indias, vacante desde la muerte de Luis Salazar y Castro en 1734. Es probable que en tal coyuntura don Gregorio quisiera atraerse a los bibliotecarios de mayor influencia, que eran Blas Nasarre y Juan de Iriarte. Así se explicaría que en 1734 le ofreciera la censura de las cartas latinas de Martí a Iriarte, cuyos versos latinos había criticado tres años antes, y a quien también le conseguiría el permiso para leer libros prohibidos. Admirado por la elegancia y la belleza de las cartas de Martí, don Juan redactó una hermosa y encomiástica censura que admiró al propio deán (Mayans y Siscar 1973, pp.368-370).

En cuanto a Nasarre, que había permitido que Mayans conociera, prologara y editara el Diálogo de la Lengua de Valdés y había aprobado su De incertis legatis (1734), don Gregorio le dedico los Orígenes de las lengua española, que se publicaría en 1737, 
y lo ayudó cuando tuvo dificultades con el inquisidor general Andrés Orbe por haber traducido ciertas obras galicanas de Claudio Fleury.

Mayans utilizó todos los medios a su alcance para obtener la plaza de cronista, y solicitó ayuda al embajador inglés, Benjamín Keene, al Marqués de la Compuesta, al Marqués de Villena, y al confesor real, Guillermo Clarke. Sin embargo, no obtuvo el decisivo apoyo de José Patiño, secretario de Estado, a quien don Gregorio obsequió con un ejemplar de su Epistolarum libri sex, y a quien dedicaría sus Pensamientos literarios en 1734. Según Antonio Mestre, Mayans pretendía que esta obra fuese su carta de presentación en la corte y su aval para la solicitud de la plaza de cronista de Indias. Pero Nasarre solicitó la plaza de cronista para Juan de Ferreras, que era el primer bibliotecario, y como Ferreras precedía a Mayans en el escalafón, hubiera sido una ofensa concederle el puesto a don Gregorio.

La animadversión de los bibliotecarios con don Gregorio se explica si tenemos en cuenta los particulares condicionantes de la carrera literaria en el siglo XVIII. En efecto, los hombres de letras debían hacer méritos (cursus honorum) para ocupar después alguna vacante empezando siempre desde abajo, pues el puesto de cualquier empleado era inmediatamente ocupado por quien le precedía jerárquicamente, de modo que se producía un desplazamiento en todo el escalafón que solo dejaba disponible la última plaza (Álvarez Barrientos, 2006). La ascensión era lenta y gradual, y estaba determinada de antemano. La concesión de la vacante a Mayans hubiera sido una ofensa a Ferreras, y, por extensión, a todos los demás bibliotecarios, que lo hubieran interpretado como un agravio, y así se explica su airada reacción. Por lo demás, podemos suponer que Nasarre no actuó solamente movido por un sentimiento corporativo, sino en defensa de sus intereses personales, pues seguramente ambicionaba la plaza de primer bibliotecario, porque Ferreras ya era muy mayor (tenía ochenta y dos años cuando fue nombrado cronista, y falleció al año siguiente). La concesión de la vacante a Mayans probablemente hubiera supuesto una amenaza a sus pretensiones.

Mayans tampoco consiguió la plaza de secretario de cartas latinas que, según él, se le había prometido, como cuenta en una carta del 30 de noviembre de 1761 a Juan de Santander. Debe advertirse que Iriarte solicitó este mismo empleo por intercesión del Duque de Béjar, aunque tampoco don Juan tuvo éxito, y aún tendría que esperar algunos años durante los cuales la plaza estuvo sin cubrir.

Al cabo, Mayans no pudo conseguir la plaza de secretario de cartas latinas ni la vacante de cronista de Indias. Y a estas decepciones se sumaba el malestar provocado por los recelos que sus pretensiones habían suscitado entre los compañeros de la Biblioteca, que se intensificarían a partir de los enfrentamientos del valenciano con el Diario de los Literatos de España, cuestión de la que nos ocuparemos a continuación.

\subsection{EL ENFRENTAMIENTO CON EL DIARIO DE LOS LITERATOS DE ESPAÑA Y LAS REALES ACADEMIAS}

En las polémicas de Mayans con el Diario de los Literatos de España, Iriarte solo se vería involucrado de forma indirecta. Según cuenta Antonio Mestre (1970, p.383; 1978, pp.134-135), el bibliotecario real Blas Antonio Nasarre había invitado a Ma- 
yans a formar parte del equipo de redacción del Diario, aunque el valenciano rechazó la oferta. En 1737 apareció el primer número, que incluía la censura de sendos libros de los valencianos Antonio Bordazar y Juan Bautista Berní, amigos de Mayans. La crítica no gustó a los autores, que dejaron al criterio de don Gregorio la oportunidad de replicar. Aunque Mayans guardó silencio, en privado hizo algunos comentarios poco favorables al Diario. En 1737 Mayans también publicó dos libros que darían lugar a grandes polémicas: Vida de Miguel de Cervantes y Orígenes de la lengua española (Mayans y Siscar 1737a y 1737b). Según Antonio Mestre, en el primero Mayans defendía la superioridad de la obra cervantina y criticaba la influencia cultural francesa en la corte, una de cuyas manifestaciones había sido la edición del Quijote de Avellaneda en 1732 a instancias de Nasarre y Agustín Montiano, que estaban muy próximos al Diario. Las críticas de Mayans no gustaron a los diaristas, pero como su defensa de la obra cervantina y su reivindicación de la cultura hispana eran difícilmente impugnables, se desquitaron en la crítica de los Orígenes, incluida en el segundo número del Diario de los Literatos. Según Mestre, Blas Nasarre incitó a los diaristas para que censuraran duramente la obra de Mayans. La crítica fue obra de Martínez Salafranca, pero Mayans también veía la mano de Nasarre, Sarmiento e Iriarte en la redacción del artículo. Don Gregorio estaba seguro de la colaboración de Iriarte porque había visto en la Biblioteca Real unas apuntaciones suyas en un ejemplar de los Orígenes, y así lo cuenta en dos cartas que conservamos (Mayans y Siscar 1972, pp.384388 y 464-467).

La réplica de Mayans al artículo del Diario no si hizo esperar, y al poco tiempo publicó, bajo el seudónimo de Plácido Veranio, Conversación sobre el Diario de los Literatos de España, que descompuso a los diaristas, quienes al punto prepararon su defensa, redactada por Martínez Salafranca e incluida en el siguiente número del Diario (1737, t. III, pp.189-386). En la réplica, Mayans defendía sus Orígenes y trataba con desdén a los diaristas, al tiempo que mostraba su respeto por Feijoo. También atacaba a quienes veladamente habían colaborado en la redacción de la censura. En su respuesta, los diaristas reconocían la participación de Manuel de la Huerta y Vega y Leopoldo Puig en la redacción del artículo y tachaban a Mayans de antiespañol usando como argumento ciertas críticas sobre algunas obras españolas vertidas por el valenciano en los Acta eruditorum de Leipzig. Lamentablemente, esta acusación de antiespañolismo llegaría a convertirse en un tópico.

En la polémica entre Mayans y el Diario de los Literatos también resultaron implicadas la Academia Española y la Real Academia de la Historia. Y no solo porque algunos académicos, como Nasarre o Montiano, eran colaboradores de la publicación, sino también porque don Gregorio había censurado el Diccionario de Autoridades en su artículo de los Acta eruditorum y había expresado privadamente su desdén por los académicos. Como señala Antonio Mestre (1981, p.59; 1999) el Marqués de Villena se había empeñado en que Mayans entrara en la Academia de la Lengua, aunque este había eludido el ofrecimiento. Don Gregorio tenía un bajo concepto de la Academia, a la que consideraba una «junta de ignorantes», y no estaba dispuesto a someterse a sus normas ortográficas. Las dificultades con las dos Academias se pusieron de manifiesto cuando Mayans, que se había encargado de la censura de la España pri- 
mitiva de Huerta y Vega (1738), intentó evitar la publicación de la obra, en la que veía un ejemplo de falsificación histórica. Según afirma Antonio Mestre (1999), la oposición de la Academia de la Lengua al propósito de Mayans llegó a tal punto que el Marqués de Villena intentó sin éxito que don Gregorio retirase su censura, al tiempo que solicitaba al Marqués de Villarias, secretario de Estado, que permitiese la publicación. En cuanto a la Academia de la Historia, resultaba natural su oposición a la prohibición si tenemos en cuenta que Huerta era miembro de la institución, y que uno de los académicos más importantes era Montiano, que ya recelaba de Mayans por sus críticas en la Vida de Cervantes. Por lo demás, don Gregorio era muy duro con la Academia en su censura, pues afirmaba que, o bien aquella había sido muy indulgente al dar aprobación a una obra fingida, o bien su ignorancia le había impedido percatarse de las falsedades. Como señala Mestre (ibíd.), la opinión de Mayans no podía prevalecer sobre el criterio de las Reales Academias. Es conocido el irrenunciable sentido crítico de Mayans y su celo en defensa de la verdad histórica. Empero, creemos que su obstinada oposición a la España primitiva obedecía también a otras razones, como veremos en seguida. Como se habrá advertido, Huerta y Vega colaboró en la crítica de los Orígenes, lo cual explica en parte la animosidad de don Gregorio en la censura de la España primitiva. La historia pudo haber sido más o menos como sigue.

En 1737 Mayans publicó su Vida de Miguel de Cervantes, en el que hacía claras alusiones a Nasarre y Montiano. A decir verdad, don Gregorio pudo haber dado mejores pruebas de prudencia omitiendo la alusiones directas a la reedición de Nasarre. Primero, porque siendo reciente seguramente aún estaría en la memoria de los lectores, y era innecesario el recurso a la cita explícita; además, porque si lo que se pretendía era censurar ciertos gustos literarios, hubiera bastado con defender la superioridad de Cervantes sobre Avellaneda sin entrar en otro particular. Es probable que don Gregorio estuviera disgustado por las censuras de los diaristas a las obras de Berní y Bordazar en 1737 y por su fracaso en la tentativa de obtener la plaza de cronista de Indias en 1734. En cualquier caso, las críticas debieron molestar a Montiano y, sobre todo, a Nasarre, que incitó a los diaristas para que censuraran duramente los Orígenes de Mayans. Estos seguramente conocerían los comentarios negativos que Mayans había hecho en privado sobre Diario de los Literarios y sobre la Academia Española, y probablemente también influyó en su ánimo el enfrentamiento de Mayans con Feijoo en 1731 a propósito de la Ortografía de Bordazar. La censura no gustó a Mayans, que respondió con dureza a los diaristas en Conversaciones. Estos replicaron en el tomo III del Diario extractando un artículo titulado «Nova literaria ex Hispania», publicado por don Gregorio bajo seudónimo en los Acta eruditorum de Leipzig en 1731. En el artículo se criticaba las obras de Feijoo y Larramendi y el Diccionario de Autoridades. Los diaristas supieron que Mayans había sido el autor por Nasarre, a quien don Gregorio se lo había contado confidencialmente. Este y otros hechos parecen indicar que Nasarre actuó con doblez. Finalmente, en 1738 se dio la censura de la España primitiva de Huerta y Vega a Mayans, que intentó impedir la publicación, pues consideraba que la obra era un ejemplo de falsificación histórica. Ciertamente a don Gregorio le sobraban razones para oponerse a su publicación, porque la España primitiva era en efecto una adaptación de un manuscrito fingido del Siglo XVII obra 
de José de Pellicer, como afirma Siles (1999); pero probablemente existían también otros motivos, porque Huerta y Vega había participado en la censura de los Orígenes, lo cual debió pesar mucho en el ánimo de don Gregorio si no en el fondo, al menos en las formas. Y adviértase también que el Diario había censurado favorablemente una obra de Huerta justo en el mismo número en que aparecían las censuras de los trabajos de Berní y Bordazar. La tenaz oposición de Mayans a la publicación de la España primitiva lo enfrentaría a las Academias de la Lengua y la Historia.

Como señalamos en el apartado anterior, durante su estancia en la Real Biblioteca, Mayans no pudo conseguir la plaza de secretario de cartas latinas ni la vacante de cronista de Indias. Y a estas decepciones se sumaba el malestar provocado por los recelos que las pretensiones de don Gregorio habían suscitado entre sus compañeros de la Biblioteca, que se intensificarían a partir de los enfrentamientos del valenciano con el Diario de los Literatos de España. De modo que la situación se iría tornando difícil para Mayans, y se haría insostenible tras su enfrentamiento con las Reales Academias en 1738. Mayans decidió abandonar la corte aquel mismo año, y el siguiente marchó a Valencia. En 1740 abandonaría definitivamente la Real Biblioteca.

\section{EL RETIRO EN OLIVA Y LOS ÚLTIMOS AÑOS EN VALENCIA (1739-1781)}

El puesto de Mayans en la Real Biblioteca fue ocupado por Manuel Martínez Pingarrón, su amigo y confidente. Gracias a Pingarrón, don Gregorio tenía noticias de la vida literaria de la corte y de las actividades y los entresijos de la Real Biblioteca. Pingarrón atendía los encargos de Mayans y le servía de intermediario cuando era necesario. La abundante correspondencia entre ambos que conservamos, publicada por Antonio Mestre, es un valiosísimo testimonio de la vida cultural de la época y de la historia de la Real Biblioteca, y nos permite examinar las relaciones de Mayans con los bibliotecarios reales (y en particular con don Juan de Iriarte) después de 1740, cuando don Gregorio ya había renunciado a su empleo en la Biblioteca y se había retirado a Oliva.

\subsection{LAS SUSPICACIAS POR LAS ANOTACIONES A LA BIBLIOTHECA DE CASIRI}

Las primeras suspicacias entre e Iriarte y Mayans después de que este dejara la Real Biblioteca surgieron a propósito de las anotaciones de Mayans a la Bibliotheca arabico-hispana escurialensis de Miguel Casiri. En efecto, y según cuenta Antonio Mestre (1970, pp.399-404), hacia 1752 Casiri ya casi había terminado la obra, pero como el estudio aún no estaba ultimado, y tenía dudas acerca de la autenticidad de la Crónica del moro Rasis, decidió consultar la cuestión a Mayans. Don Gregorio le respondió con una carta en la que demostraba la falsedad de la historia de Rasis. La respuesta gustó a Casiri, que decidió incluirla en la Bibliotheca. Como en 1753 ya estaba imprimiéndose el tomo primero, la carta se incluiría en el segundo. Por lo demás, Mayans se ofreció para corregir los errores del primer tomo, y anticipadamente los del segundo si se 
le proporcionaban previamente las pruebas de impresión. Pingarrón hizo llegar la propuesta de Mayans a Juan de Santander, que acepto la oferta. Las correcciones fueron entregadas el 11 de julio de 1763 a Santander, que las recibió complacido, al tiempo que le anunciaba a don Gregorio el envío del segundo tomo según este se fuera imprimiendo ${ }^{5}$. De todo ello se dejaría constancia en el Prólogo de la obra. En cuanto a la carta de Mayans sobre el cronicón de Rasis, Santander comunicó a Pingarrón su intención de incluirla en el segundo volumen de la Bibliotheca. Según Antonio Mestre, que se basa en lo que Pingarrón contaba a Mayans en sus cartas, Santander e Iriarte obstaculizaron y limitaron las aportaciones de don Gregorio.

En efecto, Mestre ha afirmado que Iriarte retrasó cuanto pudo la publicación del segundo tomo para publicar antes su Biblioteca griega. Sin embargo, y como él mismo señala, el comportamiento de Iriarte parece lógico si se tienen en cuenta los años que este había dedicado a la obra, cuya edición se había aprobado oficialmente en 1762. En efecto, por las cartas de Pingarrón a Mayans sabemos que don Juan estaba trabajando en la Biblioteca griega al menos desde 1753, mucho antes de que el rey ordenara en 1761 su publicación junto con el segundo tomo de la de Casiri, y debió pensar que su obra debía imprimirse primero.

Respecto de las correcciones de Mayans a la Bibliotheca de Casiri y de la inclusión en ella de su carta sobre la falsedad del cronicón de Rasis, Mestre ha señalado que Santander e Iriarte hicieron todo lo posible para limitar las aportaciones de Mayans a la obra, y tal parece ser la verdad si nos atenemos a lo que cuenta en sus cartas Pingarrón. Las correcciones quedaron reducidas a diez observaciones en el Prólogo; y la carta no fue publicada en segundo tomo porque pareció muy extensa a Iriarte y Santander, y en su lugar se incluyó una nota alusiva a la existencia de una carta en la que Mayans demostraba la falsedad del cronicón. Ahora bien, creemos que el comportamiento de los dos bibliotecarios es comprensible si tenemos en cuenta su punto de vista. Mayans había ofrecido sus correcciones sin que la Biblioteca se las hubiera solicitado previamente, comprometiendo a los dos bibliotecarios. Estos entenderían que el valenciano trataba de hacer méritos a su costa; que la inclusión de la carta sobre Rasis solo beneficiaba a don Gregorio, pues este no pertenecía a la Biblioteca; y que la aparición de una significativa serie de correcciones en la obra podía resultar un demérito para Juan de Santander, que como bibliotecario mayor era el máximo responsable de la edición. Los dos bibliotecarios debieron pensar que bastaría con la inclusión de algunos comentarios de don Gregorio en el Prólogo (en el que también se reconocía explícitamente que la obra se había entregado a Mayans para su corrección), y con una nota en el segundo tomo en la que se daba cuenta de la existencia de una carta en la que don Gregorio demostraba la falsedad de la crónica de Rasis. Por último, y a instancias de Pingarrón, Casiri también incluyó un elogio de Mayans al final del segundo tomo. A Santander e Iriarte debió parecerles más que suficiente. Es posible que don Gregorio solo quisiera vincularse a los proyectos editoriales de la Real Biblioteca, pues desde la subida al trono de Carlos III corrían nuevos tiempos, y se

\footnotetext{
${ }^{5}$ Alemany Peiró (1994, p.285) afirma que, según los manuscritos conservados en el Colegio del Corpus Christi de Valencia, el verdadero autor de las correcciones fue Juan Antonio Mayans.
} 
respiraba un aire de reformas. Pero, tal vez como consecuencia de un pasado marcado por los desencuentros, los bibliotecarios reaccionaron a sus pretensiones con suspicacia, como ya había sucedido antes, y quisieron mantenerlo al margen.

\subsection{LA POLÉMICA DEL CATÁLOGO DE LOS MANUSCRITOS GRIEGOS Y EL PLEITO DE LAS GRAMÁTICAS LATINAS}

Como hemos señalado en la introducción, la publicación del catálogo de los manuscritos griegos de la Real Biblioteca, Regiae bibliothecae Matritensis codices graeci mss., daría lugar a un nuevo enfrentamiento entre Mayans e Iriarte ${ }^{6}$. En efecto, en septiembre de 1769 la obra ya estaba impresa, y Pingarrón advertía a Mayans de que salía a relucir su nombre, aunque no precisamente para bien. Así lo contaba Pingarrón (Mayans y Siscar 1989, pp.217-218):

Matamoros y otros están durmiendo ${ }^{7}$, hasta que despierte la Biblioteca griega de Iriarte, cuyo tomo primero está ya impreso; aunque intentaba hablar a Vmd. de esto, lo reservo para una carta determinada sobre ello, en que diré a Vmd. la danza que anda y cuán mal trata Iriarte a Vmd., al deán Martí y a nuestro común y estimado amigo Pérez Bayer. No tardaré en escribirle, hablando a Vmd. al oído.

La respuesta de un desairado Mayans (1989, pp.218-219) no se hizo esperar, y en carta del 24 de septiembre le decía a Pingarrón: «Ese chocho hace bien de darme por compañero en la censura al deán de Alicante [Manuel Martí]. Adolece de envidia, mal antiguo en su ánimo. Dios le libre de ella y me confirme en el propósito de no hacer caso de él». Debe recordase que Don Gregorio, que a veces se ha tenido por el heredero espiritual de Martí, había publicado las cartas latinas y la biografía del deán de alicante, cuyo magisterio reconocía ${ }^{8}$. Adviértase también que tanto Martí como Mayans y Pérez Bayer pertenecían al grupo valenciano.

En carta del 7 de noviembre de 1769 (Mayans y Siscar 1989, pp.225-257), Pingarrón explica Mayans los pormenores de las críticas de Iriarte en su Biblioteca griega. Don Juan acusaba a Martí de hurto literario, pues había plagiado a Luis Tribaldos de Toledo unas «reglas para conservar una biblioteca». En cuanto a Pérez Bayer, Iriarte le señalaba algunos errores. Pingarrón también da cuenta de la intervención de los sobrinos de Iriarte, que querían persuadir a don Juan de que moderase su crítica a Pé-

\footnotetext{
${ }^{6}$ Para la polémica suscitada por los comentarios incluidos en el Catálogo de los manuscritos griegos, pueden verse las cartas reproducidas en los siguientes volúmenes del Epistolario de don Gregorio: Mayans y Siscar (1987, pp.423-425), Mayans y Siscar (1988, pp.452-453 ), Mayans y Siscar (1989, pp.117-119,281-282, 289-291,295-296).

${ }^{7}$ Se refiere al retraso de la edición de las obras de Matamoros.

${ }^{8}$ Tomamos de Estellés González (1999, p.203) la traducción de unas palabras latinas en las que Mayans se refiere a Manuel Martí: «Con todo sería el más ingrato de todos, si no confesara públicamente y testificara que siento una gran deuda por las importantes advertencias e indicaciones atinadísimas de esta gran personalidad. Él me ha animado a recorrer el Lacio, él, con su ejemplo, encendió e inflamó mi corazón con el amor de la sabiduría».
} 
rez Bayer, que era el preceptor de los infantes. La disputa vendría a complicarse con otro asunto que enfrentaría más aún a Mayans y los Iriarte: la pugna por las gramáticas latinas.

Tras la expulsión de los jesuitas en 1767, Mayans había acudido a Madrid con el encargo de componer un plan para la reforma de los estudios universitarios, pues se advertía que la Compañía dejaría un vacío tras su expulsión. Redactó entonces un documento titulado Idea de un nuevo método que se puede practicar en la enseñan$z a$ de las universidades de España. Sin embargo, su proyecto no llegó a realizarse, porque cada universidad propuso su propio plan. Según $\mathrm{M}^{\mathrm{a}}$. José Martínez Alcalde (1992, p.50, n. 123), la visita de Mayans a la corte, que se prolongó durante dos meses, despertó suspicacias entre los bibliotecarios reales, y particularmente en el círculo próximo a Iriarte, que temía la competencia de la gramática latina que don Gregorio preparaba. En carta del 14 de abril de 1767 (Mayans y Siscar 1989, pp.289-291; 1989, pp.61-63), Pingarrón prevenía a Mayans de que Iriarte tenía escrita una gramática, al tiempo que le instaba a terminar la suya.

En 1768 Mayans publicó Idea de la gramática en lengua latina (Valencia: por la viuda de José de Orga), y ese mismo año empezó a imprimirse su Gramática de la lengua latina (Valencia: 1768-1771). El 17 de noviembre de 1769 (Mayans y Siscar 1989, pp.230-231), le escribía a Mayans que Iriarte había logrado la protección de los infantes para su gramática. Aquel año don Juan pudo consultar la Sintaxis de Mayans, según cuenta Pingarrón en carta del 28 de noviembre (ibíd., pp.232-233). Por lo demás, y ante las negativas de Rodríguez de Castro, Santander dispuso que Cerdá y Rico ayudara a Iriarte.

Según dice Pingarrón a Mayans (ibíd., pp.281-282,289), el 15 de enero de 1771 don Juan ya tenía puesta en limpio más de la mitad de su gramática, y en marzo de ese mismo año ya se estaban pasando los pliegos para su corrección a Pérez Bayer. Por entonces Pingarrón ya sabía que Iriarte había moderado sus críticas a Pérez Bayer, y así se lo hace saber a don Gregorio (ibid., pp.289-291).

Entre tanto, y antes de que se empezara a imprimir la de Iriarte, Mayans había conseguido que el Consejo de Castilla aprobara su Gramática como texto de las siete universidades de la Corona de Aragón, según orden del 9 de marzo de 1771. Don Gregorio había empezado su «ofensiva» tiempo atrás, cuando supo por Pingarrón que Iriarte había logrado la protección los Infantes para su Gramática gracias a los oficios del Duque de Béjar, y que, de este modo, la obra terminaría imponiéndose en los Reales Estudios de San Isidro y en las universidades de Castilla.

El 2 de febrero de 1771, un mes antes de que el Consejo de Castilla aprobara su Gramática para las universidades de la Corona de Aragón y varios meses antes de que la obra de Iriarte se empezara a imprimir, Mayans escribió a Fernando de Velasco Ceballos, consejero de Castilla, para pedirle su intercesión ante el Conde de Aranda en favor de su Gramática. Aranda era presidente del Consejo de Castilla desde 1766; Mayans lo había conocido cuando era capitán general de Valencia, y mantenía correspondencia con el que entonces era su secretario, Ignacio de Heredia. Don Gregorio tuvo el apoyo del Conde de Aranda, que era el jefe del partido aragonés, al que pertenecía también Manuel Roda, secretario de Gracia y Justicia y otro de los grandes fa- 
vorecedores de Mayans. La carta que don Gregorio envió a Velasco (Mayans y Siscar, 1998, pp.407-408) es un buen testimonio de la oposición de Pérez Bayer a sus propósitos. Por lo demás, Mayans también buscó el apoyo del fiscal del Consejo de Castilla, Pedro Rodríguez Campomanes, como puede comprobarse en la correspondencia que conservamos (Mayans y Siscar, 1997, pp.513-514).

Pingarrón creía que los Iriarte pretendían hacer méritos con la publicación de la Gramática de don Juan para acomodar a Tomás, y así se lo había apuntado a Mayans en una carta enviada algunos meses atrás (Mayans y Siscar, 1989, pp.285-286). Y en efecto, y aunque no podemos saber con seguridad si estaba en lo cierto, Tomás ocuparía el puesto de su tío como traductor de la secretaría de Estado tras su fallecimiento en 1771, el mismo año en que se publicó la Gramática.

Finalmente, en 1771 se terminó de imprimir la Gramática de Mayans, y con el apoyo de Velasco, Campomanes y Aranda, don Gregorio logró que el 9 de marzo el Consejo de Castilla decretara su uso como libro de texto en las universidades de la Corona de Aragón. Para entonces la Gramática de Iriarte aún no se había imprimido, aunque Pingarrón creía que ya estaba impresa, y así se lo advirtió a Mayans (1989, pp.306308). En realidad, Pingarrón se había equivocado, y la Gramática de Iriarte aún no estaba impresa, aunque se comenzaría a imprimir muy poco después.

Según Antonio Mestre, la aprobación de la Gramática de Iriarte para la enseñanza de los Infantes tuvo importantes consecuencias, tal y como habían sospechado Pingarrón y Mayans, pues el texto se impondría en los Reales Estudios de San Isidro, y posteriormente en las universidades de la Corona de Castilla. Mayans conocía la utilidad y la importancia de la protección de los Infantes reales, y había pretendido que Pérez Bayer empleara con aquellos su Gramática como medio de imponerla en las universidades, pero Bayer se había negado. Empero, con el apoyo del Conde de Aranda y de Campomanes, don Gregorio había logrado que el Consejo decretara el 9 de marzo de 1771 que se utilizara su Gramática en las siete universidades de la Corona de Aragón. Pero inmediatamente surgieron problemas, porque las instituciones que gozaban de los privilegios de la venta de los textos se opusieron a la pérdida de sus beneficios. Las Universidades de Zaragoza, Huesca y Cervera se negaron a aceptar la Gramática de don Gregorio, y el decreto del Consejo hubo de repetirse dos veces más, el 4 de junio y el 23 de julio de 1771. Por lo demás, la polémica de las gramáticas latinas continuó tras la muerte de don Juan, como veremos en el siguiente apartado.

\subsection{LA CONTINUACIÓN DE LA POLÉMICA TRAS LA MUERTE DE DON JUAN DE IRIARTE EN 1771: LOS LITERATOS EN CUARESMA}

Dos años después de la aparición de la Gramática latina de don Juan, Tomas de Iriarte publicó Los literatos en cuaresma ${ }^{9}$, obra satírico-didáctica en la que se ocupa de la gramática de su tío y de la de Mayans. En su crítica de los métodos didácticos

\footnotetext{
${ }^{9}$ Iriarte editó la obra en 1773 con el seudónimo de D. Amador de Vera y Santa Clara. Figura en el tomo VII de sus las obras completas. Pingarrón informó a Mayans de la aparición de la obra en sendas cartas del 20 de abril y el 7 de mayo de 1773 reproducidas en Mayans y Siscar (1989, pp.412-413 y 420-421).
} 
de la época, Cicerón, uno de los personajes de la sátira de Iriarte, discurre sobre el estudio de la gramática latina a lo largo de catorce páginas, «pues la enseñanza de la latinidad es la que sirve de base fundamental a los demás estudios». Tras criticar a Nebrija y reprobar la tradición educativa española, Cicerón inicia una exposición de las bondades de la gramática de Iriarte. Las bases teóricas del nuevo método son el profundo conocimiento del idioma, el criterio de autoridad («buenos autores latinos») y algo que puede resultar novedoso: el sentido crítico («y teniendo presentes todos los métodos gramáticos de todas las naciones cultas europeas»). Las ventajas metodológicas van encaminadas a aumentar la capacidad cognitiva del discente disminuyendo el esfuerzo y las dificultades: aprendizaje en la lengua materna del alumno, mayor capacidad nemotécnica, menor esfuerzo al unificar métodos y materiales.

Pero no bastaba a Tomás la acometida contra Nebrija, le urgía también dar razón de la otra gramática en liza directa con la de su tío: la de Gregorio Mayans y Siscar. Nos interesa conocer los reparos que Tomás de Iriarte pone a la Gramática de Mayans. En primer lugar, considera que la obra, por su abultado número de reglas y preceptos, no es adecuada para cualquier tipo de alumno, de modo que su uso no puede generalizarse. En segundo lugar, censura su extensión: más de dos mil páginas sin contar la ortografía, frente a las trescientas cincuenta que cuenta la de don Juan. Censura Tomás vivamente la versificación del arte de Mayans, que por su rudeza e imperfección métrica no puede tenerse por poesía, sino por prosa, y que en nada podría ayudar al estudio del alumno, y menos a su memoria. Finalmente, el aprendizaje resultaba más rápido por el arte de don Juan que por el de Mayans. Como se advierte enseguida, estos reparos tienen causa común con los que antes hizo a Nebrija: la bondad de un método estaba en su facilidad, pues la facilidad ahorraba esfuerzos al alumno de modo que adelantaba en su progreso. Se propone un modelo educativo más moderno, comprensivo de las diferentes personalidades de los alumnos, y, por tanto, también de sus desiguales capacidades. A decir verdad, Mayans ya había expuesto argumentos muy parecidos en su Idea de la gramática en lengua latina, y las faltas que imputaba Tomás a su Gramática eran similares a los reparos que él mismo ponía a la obra de Iriarte.

La enseñanza del latín y el griego vive durante el siglo XVIII un profundo decaimiento $^{10}$. El deterioro de la latinidad procedía de la desintegración política y social del siglo XVII, y sus causas eran diversas: la falta de preparación del profesorado, la ausencia de control sobre aquel y una legislación insuficiente y anacrónica que había favorecido el intrusismo. Entre la Universidad y los maestros de primeras letras existía una plétora de preceptores o «dómines» que se ocupaban de la etapa intermedia, que entonces se dedicaba exclusivamente de la enseñanza del latín, indispensable para acceder a los estudios posteriores. Como los estudiantes de griego se veían obligados a manejar gramáticas en latín, al carecer de una escrita en castellano, una lengua seguía a la otra en su declive. La expulsión de los jesuitas en 1767 pudo agravar la situación, pues su dominio era casi absoluto en la enseñanza media. El momentáneo va-

\footnotetext{
${ }^{10}$ El deterioro de la enseñanza del latín hacia 1760 era notable. Sobre la decadencia de la latinidad puede verse Bernabé Bartolomé Martínez (1984); sobre la del griego, Concepción Hernando (1975).
} 
cío producido por su éxodo y las luchas por el control de la educación vinieron a ser problemas añadidos.

Ante este estado de cosas se imponía una reforma. Y la creación de la Academia Latina Matritense fue una respuesta, como lo fue el significativo número de gramáticas latinas publicadas en las últimas décadas del $\operatorname{sigl}^{11}$ : la de Mayans en 1768, un año después de la expulsión de los jesuitas; la de Juan de Iriarte en 1771; la de Juan A. González Valdés, director de la Academia Latina Matritense, en 1791; la del escolapio Calixto Hornero en $1792^{12}$; la de A. González Cañaveras en 1798. Este es el momento en el que aparecen también importantes estudios sobre la lengua griega.

La educación fue uno de los puntos más importantes del programa reformista ilustrado, pues, como sostenían los más idealistas, aquella conduciría a la virtud, y esta a la felicidad. La enseñanza del latín tenía un puesto muy importante por dos razones. Primero, porque la latinidad seguía siendo la base de la educación, y a su enseñanza se dedicaba la etapa intermedia. Por esto mismo, y en segundo lugar, era primordial la aplicación de métodos que facilitaran su aprendizaje y permitieran reducir el tiempo que se le dedicaba, de modo que el tiempo ganado pudiera dedicarse a otras disciplinas. Este es el contexto en el debemos entender las ideas de Tomás de Iriarte ${ }^{13}$. Por eso censura la oscuridad y la dificultad del método de Nebrija y los malos versos

${ }^{11}$ El pésimo estado de la latinidad fue lo que resolvió al rey a ordenar la composición de un diccionario latino-español, como Juan de Iriarte manifiesta en carta dirigida al Conde de Valparaíso. Como sabemos, el encargo real recayó en don Juan, como cuenta él mismo (Ochoa,1870, pp.194-197):

El Marqués de la Ensenada, en papel con fecha de Buen Retiro, 4 de febrero de 1754, me participó, de orden del Rey, que considerando Su Majestad que a la presente decadencia de la latinidad en España contribuía en gran parte la falta de un buen diccionario castellano-latino y latino-castellano, había resuelto se formase uno, que dispuesto con método fácil, precisión, exactitud, claridad y brevedad competente, comprendiese el caudal de ambas lenguas, y juntase en sí todas las calidades conducentes no solo a la enseñanza de la juventud, sino también a la común instrucción en cualquier edad [...].

${ }^{12}$ Arte de gramática latina corregido por [...] Calixto Hornero de la Resurrección del Señor [...]. Madrid: en la oficina de don Jerónimo Ortega y herederos de Ibarra. Esta gramática se editaría muchas veces, algunas para las escuelas religiosas, y siempre en Madrid: 1792, 1800, 1818, 1825, 1833, 1843, 1854, 1875, 1904. Suman nueve ediciones, una en el siglo XVIII. La gramática de Juan de Iriarte se editó veinte veces, cinco de ellas en el siglo XVIII: 1771, 1772, 1775, 1795, 1798. Para la Gramática de Mayans, no tenemos noticias de otras ediciones posteriores a la de 1771, aunque no descartamos su existencia. Ello nos da una idea de la consideración que alcanzó la obra de Iriarte, y nos muestra la necesidad de realizar estudios bibliométricos que revelen el impacto editorial de las principales gramáticas latinas de la época. La mera reconstrucción racional de los hechos parece insuficiente para valorar el verdadero alcance de las obras examinadas, y, sin este tipo de valoraciones, cualquier interpretación global de la historia de la gramática latina en el siglo XVIII parece arriesgada.

${ }^{13}$ Debe pensarse que Juan de Iriarte tendría opiniones parecidas, pues las censuras a Nebrija y Mayans en el Prólogo de su Gramática coinciden con la de Tomás. Allí mismo expone (1771, pp.III-IV) lo que sigue:

En la colocación de las materias he seguido el orden racional, metódico y científico, tratando completamente de cada parte de la oración con separación de las restantes [...]. Sin concluir las reglas que se dan acerca del verbo no se comprenden las del participio, observándose lo mismo en las demás partes de la oración. Pero como es indispensable acomodarse a la capacidad de los jóvenes, y estos encontrarán en el Tratado del Nombre, que va antepuesto, preceptos de más difícil comprensión que en el del Verbo, que ha de aprenderse después, se deja al arbitrio del maestro posponer el tiempo de la enseñanza algunos capítulos del primer Libro, que contiene la Primera Parte de la Etimología, y aún omitir en el discurso de toda la Gramática aquellas reglas que solo se establecen para los que aspiren al delicado conocimiento de ciertas propiedades de la lengua latina, o quieran consultar algunas dudas que sobre ella pueden ofrecérseles. 
de la extensa gramática de Mayans: porque el aburrimiento y la severidad, o desalentaba a los jóvenes, o los entretenía en exceso. Las páginas que Iriarte dedica a la gramática latina en Los literatos en cuaresma, obra olvidada por la gramaticografía española hasta hace poco ${ }^{14}$, contienen los fundamentos de un programa didáctico para la gramática que forma parte de otro más amplio y general: el proyecto educativo ilustrado. Lo que ciertamente nos permite ponderar el valor de la enseñanza de la gramática en el siglo XVIII.

\subsection{LA INTERVENCIÓN DE LOS IRIARTE}

Pese a las tres órdenes del Consejo de Castilla para que la Gramática de Mayans se utilizara en las universidades de la Corona de Aragón, podemos suponer que en 1774 los Iriarte habrían conseguido, con la ayuda de su protector el Marqués de Grimaldi, primer secretario de Estado, que en la Corona de Aragón también se pudiera estudiar por la de Iriarte o por cualquier otra escrita en verso castellano (en alusión a la de los escolapios). Al menos esto es lo que puede deducirse de la carta enviada por Mayans a Manuel Roda el 10 de enero de 1778 (Mayans y Siscar 1990, pp.299-306). Debe advertirse que entre Aranda y la secretaría de Estado existía una lucha que terminaría con el traslado del conde a la embajada de París. Naturalmente, podemos pensar que la secretaría de Estado apoyaría la Gramática de Iriarte en oposición a la de Mayans, patrocinada por Aranda desde la presidencia del Consejo de Castilla (Mestre Sanchis 1970, p.435).

Fernando de Velasco, consejero de Castilla y protector de Mayans, también veía la mano de los Iriarte en la oposición de las Universidades a la Gramática de Mayans, y así se lo comenta a don Gregorio en una carta escrita a principios de febrero de 1778, de la que también se deduce claramente el apoyo de Campomanes a la causa de Mayans (reproducida en Mayans y Siscar 1998, p.576).

\subsection{LA PUGNA POR LAS GRAMÁTICAS LATINAS EN VALENCIA}

La lucha por las gramáticas latinas fue especialmente tenaz en Valencia. En efecto, y como ha señalado Salvador Albiñana (1981), cuyas ideas seguiremos, las tres órdenes del Consejo de Castilla para que se utilizara la Gramática de Mayans en las siete universidades de la Corona de Aragón habían sido modificadas en 1774 por una nueva orden en la que se daba libertad para adoptar la obra de don Gregorio, la de Iriarte o cualquier otra escrita en verso castellano. En la Universidad de Valencia, el claustro general de catedráticos escogió el texto de Mayans, pero el arzobispo Fabián y Fuero, canciller de la Universidad, ordenó que se utilizara la Gramática de Iriarte. Para legitimar su decisión, Fabián y Fuero convocó irregularmente al claustro mayor, que

\footnotetext{
${ }^{14}$ Sobre las valoraciones del Arte de Nebrija en relación con la polémica entre Mayans e Iriarte a propósito de las gramáticas latinas véase Tubau (2004) y Salas Salgado (2005).
} 
era el máximo órgano legislativo de la Universidad, y en el que mayoritariamente se decidiría acatar la orden del canciller, a pesar de las protestas de quienes se oponían a su intervención porque vulneraba la supremacía claustral.

Las dificultades de Mayans para imponer su Gramática en la Universidad de Valencia ponen de manifiesto que los Iriarte solo eran una parte del problema. En efecto, los opositores de don Gregorio eran muchos y poderosos: las instituciones que veían en peligro los beneficios de la venta de las gramáticas; los escolapios, que aspiraban a ocupar el hueco dejado por los jesuitas en la enseñanza tras su expulsión; los tomistas, con ramificaciones en el Ayuntamiento y la Universidad; y, sobre todo, el arzobispo Fabián y Fuero, canciller de la Universidad, y Francisco Pérez Bayer, preceptor de los Infantes reales.

Respecto del arzobispo, con quien Mayans ya había tenido alguna diferencia, debemos recordar que no solo se opuso a la Gramática de don Gregorio, sino también a la retórica que este quiso implantar en la Universidad de Valencia. Nos referimos al Organum rhetoricum et oratorium publicado en Valencia en 1774. Se trata de un trabajo de síntesis compuesto por una obra de Nebrija y otra de Pedro Juan Núñez con notas del propio Mayans, que quería introducirlo como manual de retórica en el Estudio General. Pero don Gregorio tropezó de nuevo con las oposición de los tomistas y de Fabián y Fuero, que no solo se opusieron a la Gramática latina, sino también al Organum rhetoricum. Ante la negativa del arzobispo, que equivocadamente ordenó que se utilizara la retórica de la Gramática de Iriarte, que no contenía tal, Mayans expuso sus quejas al Marqués de Almodóvar y a Campomanes, como puede comprobarse en la correspondencia que conservamos (Mayans y Siscar 1997, pp.622-626). Y lo mismo hizo con Fr. José de Castro, Provincial de los franciscanos descalzos (Albiñana 1981, pp.426-428).

Mayans también se quejó a Juan Bautista Muñoz de la arbitrariedad y los abusos del arzobispo en carta del 24 de diciembre de 1774 (Mayans y Siscar 2000, pp.379380), que concluye diciendo lo siguiente de la Gramática de Iriarte:

¿Qué tal es la Gramática de Iriarte? Vmd. lo sabe: obscura en las reglas, falta de ejemplos, larga en comparación de la mía, si se cotejan las reglas y excepciones, que son el cuerpo de la gramática, errónea en muchas reglas, llena de ripios, y con mil tachas más, que callo. Verbum non amplius addam, porque es víspera de Navidad.

Y todavía en 1778 recuerda a su protector Manuel Roda, secretario de Gracia y Justicia, lo sucedido (Mayans y Siscar 1990, pp.299-306):

¿Pues qué diré del Órgano retórico y oratorio de los maestros Nebrija y Núñez? Sin saber nada el Consejo [de Castilla], pero de orden que se dijo suya, se mandó estudiar la retórica de Iriarte, diciendo que estaba incluida en su gramática, no habiéndola escrito ni aun fuera de ella. Se enseñaba dicho Órgano; ya no se enseña.

En cuanto a Francisco Pérez Bayer, su relación con Mayans fue ambigua. Bayer era el jefe del grupo valenciano, tenía el apoyo de Manuel Roda, y como preceptor de los Infantes también quería controlar los estudios de la corte, además de la Uni- 
versidad de Valencia ${ }^{15}$. Así se explica que sus intereses chocaran con los de Mayans, a quien no obstante favoreció apoyando su nombramiento de alcalde de casa y corte y la concesión de una pensión vitalicia. Empero, Bayer no podía defender la Gramática de Iriarte en Madrid y la de Mayans en Valencia sin incurrir en una evidente contradicción, y lo primero era inexcusable si quería ver publicada la traducción de Salustio del Infante don Gabriel. Por lo demás, su pretensión de controlar el mundo intelectual valenciano a través del Cabildo y la Universidad podía obligarle a un juego político que no favorecía a don Gregorio. Recurriendo al clientelismo político, sirviéndose de su privilegiada posición en Madrid y del apoyo de Roda, Bayer podía colocar en Valencia a hombres de su confianza que cuando eran llamados a Madrid contribuían a fortalecer su posición. Así pues, el juego político entre la corte y Valencia era similar al que se establecía entre la secretaría de Estado y las embajadas ${ }^{16}$, e inevitablemente Mayans se hallaba en medio de este complejo mundo de intereses, y tuvo que sufrir las consecuencias. La amistad de Pérez Bayer y don Gregorio se prolongó durante casi cincuenta años, y aunque ambos podían compartir algunas ideas en el contexto del reformismo ilustrado, la oposición de Bayer quizá fuera el principal obstáculo en la carrera de Mayans en la segunda mitad de la centuria.

\section{LAS RAZONES DEL ENFRENTAMIENTO Y DE SUS CONSECUENCIAS}

Hasta aquí el relato de los enfrentamientos entre Mayans e Iriarte según hemos podido reconstruirlo a partir de los datos históricas que tenemos, de las noticias de Antonio Mestre y de la correspondencia de don Gregorio y de Manuel Martínez Pingarrón. Se impone ahora una valoración, y, en efecto, podemos plantear algunas hipótesis explicativas que nos permitirán entender más adecuadamente las disputas entre Mayans y los Iriarte. Debe advertirse no obstante que cualquier tentativa en este sentido pasa por una mejor comprensión de la personalidad y la biografía del propio Mayans, lo cual por cierto pudiera parecer un objetivo excesivo. Empero, este es el reto que debemos aceptar.

En primer lugar, es preciso señalar que las aspiraciones de los Iriarte eran tan legítimas como las de don Gregorio. Ambos grupos sabían que los jesuitas habían dejado un vacío tras su expulsión, y, en el contexto de la reforma cultural y educativa propiciada por Carlos III, advertían que sería necesaria una nueva gramática latina. Iriarte estuvo trabajando en el primer tomo de su Biblioteca griega hasta 1769. Entonces empezó a ocuparse de su Gramática animado por su sobrinos, que estaban em-

\footnotetext{
15 Según Mestre Sanchis (1978, pp.239-240), la conexión de Pérez Bayer con el partido aragonés se limitaba a su relación con Manuel Roda y al apoyo mutuo en una serie de reformas generales deseadas por todos los ilustrados. No obstante, el apoyo de Roda le daba a Bayer una «gran capacidad de intriga».

${ }^{16}$ Linch (2007, pp.142-159) ha señalado que la política de la España dieciochesca se caracterizaba por el clientelismo político y la lucha de facciones, que afectaban a grupos de intereses y equipos ministeriales. Ha señalado también (ibíd., p.168) la importante participación de la burocracia y los servidores reales en el juego político.
} 
pleados en la secretaría de Estado. Como don Juan ya estaba muy enfermo, se dispuso que le ayudara Rodríguez de Castro, y más tarde, y ante los reparos de este último, Cerdá y Rico. Por su parte, Mayans había acudido a la corte en 1767 con el encargo de presentar un plan para la reforma de los estudios universitarios. Redactó entonces un documento titulado Idea de un nuevo método que se puede practicar en la enseñanza de las universidades de España. En 1768 publicó su Idea de la gramática en lengua latina, y ese mismo año comenzó la impresión de su Gramática, que terminó de imprimirse en 1771, antes de que hubiera concluido la suya Iriarte, que en 1769 pudo consultar la Sintaxis de Mayans. Ahora bien, don Gregorio conocía la existencia de la Gramática de Iriarte desde 1767, porque Pingarrón se lo había comentado poco después de su visita a la corte, al tiempo que lo instaba para que terminase la suya. En 1769 Pingarrón contó a Mayans que los Iriarte habían logrado el apoyo de los Infantes reales con la mediación del Duque de Béjar. Mayans sabía lo que esto significaba, porque en 1767 había intentado que Pérez Bayer adoptara su Gramática para la enseñanza de los Infantes como un medio para imponerla después en las Universidades castellanas. No obstante, y por razones que ignoramos, aunque podemos suponer que temía la rivalidad de Mayans, Bayer se había negado. Ante las novedades que le comunicaba Pingarrón, don Gregorio se apresuró, y, con la ayuda de Velasco, Campomanes y el Conde de Aranda, logró que el 9 de marzo de 1771 el Consejo de Castilla aprobara el uso de su Gramática en las siete universidades de la Corona de Aragón. Para entonces, la Gramática de Iriarte aún no se había empezado a imprimir. Ante la oposición de quienes temían perder los beneficios derivados de los privilegios de impresión, el Consejo tuvo que repetir su orden el 4 de junio y el 23 de julio del mismo año. De este modo, don Gregorio había conseguido preservar un importante ámbito de influencia para su Gramática, adelantándose a la impresión de la obra de Iriarte, a quien la protección de los Infantes le garantizaba la difusión de su obra en las universidades de Castilla. No obstante, en 1774 los Iriarte consiguieron con la ayuda del Marqués de Grimaldi que en la Corona de Aragón también se pudiese estudiar por la gramática de de don Juan o por cualquier otra escrita en verso castellano, lo que suponía una reducción de los privilegios previamente concedidos a Mayans. Pero el mayor revés lo sufriría don Gregorio en la Universidad de Valencia, cuyo claustro, manipulado por el arzobispo Fabián y Fuero, se opuso a su Gramática. Ahora bien, la negativa de la Universidad no parece un resultado de las maquinaciones de los Iriarte, sino de la fuerte oposición de los escolapios, de los tomistas, del arzobispo y de quienes temían perder los beneficios de los privilegios de impresión. Mayans contaba, sobre todo, con la oposición de Pérez Bayer, que quería controlar la vida intelectual de Valencia y los estudios de la corte. Así pues, se trataba de utilizar la Gramática de Iriarte para rechazar la de don Gregorio.

De modo que los Iriarte no hicieron nada más que defender su Gramática más o menos como lo hubiera hecho el mismo don Gregorio, que no solo contó con importantes apoyos en el Consejo de Castilla, sino que en su correspondencia desarrolló una campaña a favor de su Gramática y en contra de la de Iriarte, como se habrá advertido en las páginas anteriores. Y por cierto que don Gregorio también tuvo que sufrir una campaña orquestada para desprestigiar su Gramática mediante unas cartas en- 
viadas desde Valencia a varias universidades europeas. Por lo demás, los intereses de Mayans no eran tan distintos a los de los Iriarte, pues más allá de ciertos tópicos sobre el provecho y la gloria de España, los Iriarte, al parecer, pretendían emplear a Tomás en la secretaría de Estado, mientras que a Mayans le preocupaban los privilegios de la impresión de su Gramática, concedidos por el rey "para dos vidas, la mía y la de un hijo, el que yo elija» ${ }^{17}$.

Que los intereses de Mayans no eran solo intelectuales, sino también materiales, y que la oposición de la Universidad de Valencia no se debía solo a las intrigas de los Iriarte, sino a la oposición del arzobispo Fabián y Fuero y de otros sectores, lo prueba el hecho de que don Gregorio tampoco consiguiera implantar su Organum rhetoricum et oratorium. En efecto, la expulsión de los jesuitas no solo había dejado un vacío en la enseñanza de la gramática latina, sino también en la de la retórica. Don Gregorio debió advertirlo, y pese a los fracasos experimentados con la Gramática, en 1774 trató de imponer en la Universidad de Valencia su retórica. Sin embargo, y para su desgracia, el arzobispo se opuso a la obra de Mayans.

En realidad, las dificultades de don Gregorio para impulsar su carrera literaria en la primera mitad de siglo se debieron a su incapacidad para encontrar un mecenas. En efecto, el apoyo de un protector era imprescindible para los hombres de letras, pues las alternativas eran muy limitadas para quienes pretendían subsistir de la literatura: el mecenazgo de algún noble, el patronazgo real, dispensado mediante la colocación en alguna academia o la asignación de una pensión, y el acceso a un débil mercado literario del que estaban exentas las obras de erudición y la poesía, y que en todo caso era una opción viable solo para quienes quisieran dedicarse a la literatura dramática, el periodismo, las obras de carácter divulgativo o religioso o la traducción, y aun esto con tales limitaciones y dificultades que hacían necesaria una fuente de ingresos suplementaria. Don Juan de Iriarte contó desde el primer momento con el decisivo apoyo del Duque de Béjar; Mayans, en cambio, no consiguió el favor del cardenal Hércules Fleury ni el de José Patiño, y solo con la subida de Ensenada, que le encargó la redacción de las Observaciones al concordato de 1753, pudo vislumbrar una cambio de su situación, aunque la caída de Ensenada en 1754 frustraría las expectativas de mejora. Respecto del cardenal Fleury, primer ministro de Luis XV, debemos recordar que Mayans le dedicó Tractatus academici de Puga y Epistolarum libri duodecim de Martí, dedicatoria que por cierto no gustó en ciertos ambientes de la corte. Antonio Mestre (1985, pp.144-145) afirma que don Gregorio pretendía in-

\footnotetext{
${ }^{17}$ Carta de Mayans al Marqués de Almodóvar fechada el 21 de febrero de 1775 (Mayans y Siscar 1997, pp.624-266): «Por estas y otras causas, me he visto obligado a defenderme vigorosamente, pidiendo que se mande enseñar por mi gramática, para cuyo fin me concedió el rey N. Sr. un privilegio para dos vidas, la mía y la de un hijo, el que yo elija. No hay razón [para] que el arzobispo [Fabián y Fuero] malignamente quiera privar al público de la doctrina que no puede restituirle, y a mí de las mercedes del rey». Véase también la carta a Velasco del 11 de noviembre de 1774, en la que don Gregorio expone las mismas ideas (Mayans y Siscar 1998, pp.491-492): "Aquí se trata de quitarme el privilegio que el rey me ha concedido por dos vidas para que se enseñe mi Gramática en este reino de Valencia y de privar al público de la enseñanza de mi Gramática, mandada dar por el Consejo [de Castilla] y aceptada y puesta en práctica por la Universidad [de Valencia]».
} 
troducirse en el mundo cultural francés y acaso un empleo en la biblioteca del rey de Francia, pero el silencio del cardenal pronto lo desengañaría. Don Gregorio envió 12 ejemplares de las cartas latinas a Fleury. También envió un ejemplar a Baltasar Patiño, marqués de Castellar y embajador español en Francia. Baltasar era hermano de José, y podemos suponer que este estaría al tanto de la pretensión de don Gregorio de introducirse en el mundo intelectual francés. Acaso los hermanos Patiño no vieran con muy buenos ojos estos movimientos, y tal vez aquí se halle el origen de la antipatía de José por don Gregorio. Finalmente, la situación de Mayans mejoraría a mediados de siglo, tras el ascenso de Roda y el Conde de Aranda a la secretaría de Gracia y Justicia y a la presidencia del Consejo de Castilla respectivamente. En 1766 don Gregorio consiguió el nombramiento honorífico de alcalde de casa y corte de Madrid y la asignación de una pensión. Empero, sus posibilidades de acción se verían muy limitadas por los intereses contrapuestos de Pérez Bayer, como ya hemos señalado. Este es el contexto preciso en el que hay que valorar los efectos y el verdadero alcance de la rivalidad entre Mayans y los Iriarte.

Según Antonio Mestre, la leyenda sobre el antiespañolismo de don Gregorio, que después se impondría tan injustamente, se debe a las acusaciones del Diario de los Literatos $^{18}$. Y añade que esta idea debió pesar en el ánimo de José Patiño, que se opuso a la concesión de la plaza de cronista de Indias al valenciano. Pero a decir verdad, esto sucedía en 1734, y el artículo del Diario con el extracto de los Acta eruditorum salió a fines de 1737, de modo que el recelo de Patiño debe tener otro motivo, y acaso se deba al pasado austracista de Mayans, a su intento de introducirse en los círculos culturales franceses y a sus relaciones con Benjamín Keene, embajador inglés. En efecto, y como afirma el propio Mestre (Gregorio Mayans y Siscar, 2002), Mayans tenía miedo de que se conocieran sus vistas a casa de Keene, que, no lo olvidemos, era el embajador de una potencia rival que además había luchado contra los derechos de Felipe V en la Guerra de Sucesión. Si se advierte el pasado austracista de don Gregorio se entenderá fácilmente su anglofilia (y de paso, y en parte, también su francofobia a propósito de sus críticas al afrancesamiento y a la edición del Quijote de Avellaneda de 1732). Pero su relación se conoció pronto, porque, entre otras cosas, Keene pagó la edición del Epistolarum libri XII de Manuel Martí, propuso a don Gregorio la redacción de la biografía de Cervantes y se ofreció a interceder ante Patiño para conseguir la plaza de cronista de Indias. Mayans pensaba que los oficios de Keene ante Patiño lo favorecerían, pero creemos que en realidad sucedía todo lo contrario, pues podemos suponer cuál sería la reacción del secretario de Estado a los oficios del embajador. Para hacernos una idea de la capacidad de intriga de Keene, bastará con recordar que, junto con el Duque de Huéscar, el Conde de Valparaíso y Ricardo Wall, propició la caída de Ensenada en 1754, lo que frenó las reformas que se venían acometiendo. Por lo demás, como la biografía de Cervantes había

\footnotetext{
${ }^{18}$ Mestre Sanchis (1970, p.424) afirma que la opinión sobre el antiespañolismo de Mayans puede encontrarse «en los círculos más dispares», lo que prueba que se trata de «un hecho real» y no de algo imaginado por don Gregorio. Mestre aporta el testimonio de Diego de Arredondo, que señala a Montiano, Luzán, Sarmiento e Iriarte entre quienes difundían esta opinión.
} 
sido un encargo de lord Carteret con el propósito de regalar una edición del Quijote a la reina de Inglaterra, las críticas de Mayans al afrancesamiento de la corte española y al exceso de juntas y academias en un libro que iba a ser regalado al soberano de una potencia extranjera que rivalizaba con España no debió sentar muy bien en España. Finalmente, el pragmatismo de Patiño también explica su desinterés por los proyectos de reforma literaria de Mayans. Como el conocimiento no siempre es incompatible en los hombres con la inocencia, sino que muchas veces andan juntos, solo una excesiva confianza de don Gregorio en su propia valía pudo llevarlo a pensar que las consideraciones sobre sus méritos estarían por encima de las cuestiones de Estado y de la alta política. Y en efecto, una desmedida ambición y una excesiva arrogancia parecen haber sido notas distintivas de la personalidad de don Gregorio, que en vísperas de su partida a la corte escribía al Manuel Martí «o César o nada» (cit. por Mestre Sanchis 1981, p.53). Y acaso también explican en parte su aislamiento y sus dificultades.

Pere Molas ha editado un memorial inédito de Mayans dirigido a Carlos III en $1766^{19}$. En el documento, don Gregorio expone oficialmente ante el monarca sus méritos con el propósito de obtener su favor. Lo que nos interesa ahora es la descripción que don Gregorio hace de sí mismo en la exposición de sus méritos. En efecto, Mayans se presenta como un adelantado de la Ilustración en sus primeros momentos, y manifiesta el predicamento de que gozó como catedrático en Valencia, a «donde la juventud de muchos reinos y provincias de España acudió a oírme». Don Gregorio se presenta también como «el primero y único que he formado cánones etimológicos de la lengua española» y como el «descubridor de los tesoros ocultos de la lengua española y el renovador de la oratoria sagrada». Su Gramática latina era «lo más copiosa, clara y útil que tenga hasta hoy cualquier nación extranjera»; y su obra de lógica (la Razonatoria), «empresa hasta hoy no practicada».

Basten estos pocos ejemplos para mostrar la conocida arrogancia intelectual de don Gregorio. Nos interesa advertir ahora que esta actitud no facilitaría su relación con los intelectuales de la corte. Ya hemos señalado las muy severas y probablemente innecesarias alusiones a Nasarre y Montiano a propósito de la edición del Quijote de Avellaneda (dice que «no hay hombre de buen gusto que haga aprecio de él»); su desprecio de la obra de Feijoo, acreditado desde fecha bien temprana, en 1731, cuando publicó sus comentarios en los Acta eruditorum ${ }^{20}$; y su pretensión de obtener la plaza de cronista de Indias, que inquietó a los bibliotecarios ${ }^{21}$. Podemos añadir también su negativa a formar parte del Diario de los Literatos y de la Real Academia con el pretexto de su ínfi-

\footnotetext{
${ }^{19}$ Molas Ribalta (1981) localiza el documento en el Archivo General de Simancas, sección de Gracia y Justicia, leg. 820, y señala la existencia de otro memorial muy similar dirigido a Roda.

${ }^{20}$ El artículo se publicó en septiembre, y la carta de Mayans publicada con la retractación de Feijoo a propósito de la Ortografía de Bordazar tiene fecha del 7 de noviembre. Esto nos permite deducir que la animadversión de don Gregorio era anterior a su polémica con el benedictino.

${ }^{21}$ Manuel Martí había escrito a Mayans en 1736 que el puesto de simple bibliotecario no era digno de él, y que debía aspirar al de primer bibliotecario, pues los demás bibliotecarios, decía, no eran otra cosa que «barrenderos de librería». Sorprendentemente, Mestre Sanchis (2000, p.28, n.18), de quien tomamos la cita, afirma que las palabras de Martí eran esencialmente ciertas pese a su brusquedad.
} 
mo nivel intelectual ${ }^{22}$. Sin embargo, don Gregorio formó la Academia Valenciana, y no hay razones para suponer que el nivel intelectual de esta fuera muy distinto del de la Academia Española. El verdadero problema residía en la dificultad del propio Mayans para aceptar otro magisterio que no fuera al suyo. Esta limitación lo condenó a cierto aislamiento justamente en el siglo en que se estaba imponiendo el trabajo corporativo en el ámbito de las letras (academias, sociedades, periódicos, tertulias). Al desvincularse de la Academia de la Lengua y la Real Biblioteca, don Gregorio quedaba al margen del proyecto editorial y cultural de la Monarquía. Podría argumentarse que Mayans tuvo que enfrentarse a los intelectuales de la corte, un grupo de poder que controlaba la vida cultural y se oponía a quienes llegaban de provincias. Y en efecto así fue, pero debe advertirse que esta situación, ni afectó exclusivamente al valenciano, sino también a otros intelectuales, como los hermanos Mohedano, ni se dio solo en Madrid, sino que fue común a París, Londres y otras cortes europeas ${ }^{23}$. Por lo demás, y como él mismo reconoce en sus cartas, quizá el mayor obstáculo que encontró Mayans cuando ya se había retirado a Oliva fue la oposición de Pérez Bayer, otro valenciano afincado en la corte, cuyos intereses eran incompatibles con los de don Gregorio, como hemos visto a propósito del pleito de las gramáticas latinas.

Convertir a Mayans en una víctima de un supuesto conflicto entre el centro y la periferia ${ }^{24}$ durante nuestra centuria ilustrada puede resultar atractivo políticamente, y, por diversas razones, que van desde lo histórico hasta lo ideológico o lo puramente psicológico, agradará a más de uno; pero, desde luego, no es la mejor manera de hacer justicia a su obra, sino, al cabo, una forma de menoscabar y alterar su auténtico, esencial e indiscutible valor. Y otro tanto podría decirse de la teoría que presenta a Mayans como el principal representante de cierto humanismo cristiano (lo cual puede ser cierto) que vendría a ser la quintaesencia de una ilustración cristiana (lo cual resulta mucho más dudoso).

A propósito de la personalidad de Mayans, Javier Cruzado (1945, p.135) ha afirmado lo siguiente:

[...] hombre fácilmente irritable, puntilloso en extremo, con susceptibilidad muy próxima a una intolerable egolatría. Su orgulloso retraimiento, el desprecio con que

\footnotetext{
${ }^{22}$ Mestre Sanchis (2000, pp.36-37) afirma que Mayans, que había sido atacado por el Diario, persuadió al P. Clarke, confesor real y director de la Real Biblioteca, del escaso valor de los trabajos literarios de Martínez Salafranca, uno de sus editores, lo que contribuyó a que aquel retirara su apoyo a la publicación. Muerto Campillo, y perdido el favor de Clarke, el periódico estaba condenado a la desaparición. Empero, el propio Mestre Sanchis (1976, p.134) afirma que la censura que hizo el Diario de los Orígenes era «dura, pero sistemática y bien estructurada», tanto que gustó mucho a Manuel Martí, y llevó a Menéndez Pelayo a pensar en unos colaboradores de Martínez Salafranca, como también había sospechado Mayans.

${ }^{23}$ Así lo afirma Álvarez Barrientos (1999), y señala que los granadinos se quejaron de forma notable de tal discriminación. Añade además que esta situación también se dio en otras ciudades europeas, y que a menudo fue criticada por los eruditos locales. En España, el grupo de poder de la corte estaba formado por Nasarre, Montiano, Juan de Iriarte, Ferreras, Martínez Salafranca, Luzán, Huerta, Sarmiento, Feijoo y otros literatos.

${ }^{24}$ Perdomo-Batista (2011c) ha cuestionado la existencia de una supuesta «Ilustración local o periférica» contrapuesta a otra «central».
} 
miraba la obra de los demás y una supervaloración de la suya propia le hacían recelar de sus contemporáneos y considerarse preterido por ellos. No es infrecuente verlo presentándose en el papel de víctima, de hombre relegado por otros de menos valía.

Las conclusiones de nuestro examen de la correspondencia de don Gregorio y de las polémicas literarias en las que se vio involucrado coinciden bastante con el análisis de Cruzado. Ciertamente Mayans no obtuvo la plaza de traductor de la secretaría de Estado ni la de cronista de Indias, pero tampoco Iriarte alcanzó la de bibliotecario mayor, y tuvo que esperar catorce largos años antes de conseguir la de traductor, que estuvo vacante durante ese tiempo. Es verdad que en 1751 se le concedió a Iriarte una pensión anual de trescientos pesos «en atención a su erudición y a lo mucho que ha trabajado en esta biblioteca», como cuenta Pingarrón a don Gregorio (Mayans y Siscar 1987, pp.368-369); pero también lo es que Mayans obtuvo el ansiado reconocimiento en 1766. Y si don Juan de Iriarte tuvo el apoyo del Duque de Béjar, Grimaldi, Nasarre, Santander, la Secretaría de Estado y sus sobrinos; Mayans gozó del favor del cardenal Cisneros, el Marqués de la Compuesta, Fernando José de Velasco, Ensenada, Roda, Campomanes y Aranda. Para no hablar de la ayuda de su hermano Juan Antonio y de la complicidad de Martínez Pingarrón, que facilitaba a don Gregorio información de los proyectos y los movimientos de la Biblioteca. Adviértase además que Mayans logró que el Consejo aprobara su Gramática para las Universidades de la Corona de Aragón, lo cual no es poco si tenemos en cuenta los intereses y las poderosas fuerzas en juego, aunque la orden fue modificada posteriormente, limitando el privilegio absoluto que se le había concedido a don Gregorio. Finalmente, debe recordarse también que Mayans consiguió colocar a su hijo José María en la carrera judicial y a su hermano Juan Antonio en una canonjía.

El pleito de las gramáticas latinas no fue provocado solo por la ambición de los Iriarte, sino que en él confluyeron múltiples y complejos factores: el interés material e intelectual de los Iriarte, que querían colocar a Tomás y buscaban el prestigio y los beneficios que podría reportarles la impresión de la Gramática de don Juan; el interés intelectual y material de Mayans, a quien el rey había concedido los privilegios de impresión de su Gramática por dos vidas; las ambiciones de Pérez Bayer, sometido a un juego de influencias y clientelismo político con el que quería controlar la vida cultural de Valencia y de la corte; las ambiciones de los escolapios, que pretendían ocupar el vació dejado por los jesuitas; las pretensiones del arzobispo Fabián y Fuero y de los tomistas de Valencia; la pugna entre la secretaría de Estado y el Consejo de Castilla, presidido por el Conde de Aranda, o, si se prefiere, entre el centralismo borbónico y el antiguo sistema conciliar, vinculado a los derechos forales; y, finalmente, el deseo de renovación en el contexto del reformismo cultural y educativo carolino. Naturalmente, las gramáticas latinas no fueron sino las armas empleadas por unos y otros en tan difícil contienda, y sorprende la diversidad y complejidad de los factores que entran en juego, y lo lejos que pueden llegar sus implicaciones y consecuencias. Una complejidad que quizá debiera servirnos de ejemplo y advertencia cuando queramos examinar la historia de la filología y la lingüística más recientes.

A decir verdad, Mayans vivió de forma dramática sus propias contradicciones y las de su época: por un lado, está inserto en la tradición humanista de la Corona de 
Aragón, muy influida por Vives; un humanismo auténtico y de raíces erasmianas, crítico y opuesto a la escolástica. Por otro, su pasado austracista y sus orígenes lo aproximan al foralismo, es decir, al sistema conciliar de los Austrias, necesariamente vinculado al espíritu caballeresco, a la mentalidad señorial. Así se explica que en 1772 Pingarrón le enviara un espadín para su hijo Miguel y que este llevara la vida de un noble; así se explica también la fórmula empleada por Mayans en los títulos de algunas de sus obras: Gregorii Maiansii, generosi valentin ${ }^{25}$. Pues aunque a menudo suela pasarse por alto, lo cierto es que el movimiento ilustrado no pretendía modificar el Antiguo Régimen, y aquí radica precisamente una de sus más agudas y difíciles contradicciones. Mayans pertenece a una suerte de intelectualidad aristocrática, como si fuera un humanista del siglo XVI, lo cual explica su elitismo y sus diferencias con Feijoo. En realidad, hay dos hechos que explican muy bien sus diferencias con el benedictino.

En primer lugar, ambos tienen una distinta concepción de la República de las Letras. Muy apegado todavía al Parnaso literario, Mayans tiene una concepción elitista según el modelo tradicional; en cambio, Feijoo es un divulgador y un creador de opinión, y en él ya se ha producido esa ampliación de los límites de la República Literaria que, unida a las nuevas formas de socialización del escritor y a los nuevos modos de producción y difusión de la cultura, caracteriza la centuria ilustrada. Esta progresiva ampliación de la República Literaria, que va siendo sustituida en parte por la idea de cosmopolitismo, iría desdibujando los límites de aquella hasta hacerla desaparecer.

En segundo lugar, y en estrechísima relación con lo anterior, en Mayans no llega a consumarse totalmente la transformación del humanista en el hombre de letras moderno. Seguramente ello se debe en gran medida a la difícil personalidad del valenciano, que lo apartaba de los nuevos modos de socialización de la cultura (sociedades, tertulias, academias, periódicos). Y lo cierto es que don Gregorio utiliza preferentemente los métodos tradicionales para la difusión y puesta en práctica de sus ideas y proyectos: la carta y el apoyo de los poderosos; y que vio fracasar sus intentos de introducirse en los nuevos usos, como la creación de la Academia Valenciana o su aproximación a la Real Biblioteca. Pensar que el origen de sus dificultades se halla sobre todo en su irrenunciable deseo de independencia es un error, pues sin negar este, resulta evidente que existen otros importantes factores que deben ser tenidos en cuenta. Es notable la diferencia que puede advertirse entre la conducta de don Gregorio y la de, por ejemplo, Tomás de Iriarte, cuya activa vida social es bien conocida. Tachar a Tomás de frivolidad, esnobismo o afrancesamiento significaría no entender en absoluto el proceso de transformación que se está produciendo en esos momentos, y en

\footnotetext{
${ }^{25}$ Lo primero lo sabemos por una carta de Pingarrón a Mayans del 18 de febrero de 1772 (Mayans y Siscar, 1989, pp. 336-337). Mestre Sanchis (1999, cap. VIII) afirma que el hijo mayor de Mayans no era apto para los estudios, y no pasó por la Universidad. Heredero de los bienes vinculados, salía de caza con el Conde de Faura, y hacía la vida de un noble. Como acabamos de señalar, don Gregorio le compró un espadín. En cuanto a lo segundo, F. López (1999, pp.97-98) ha señalado que Mayans apreciaba mucho el título de generosi que había heredado y le gustaba exhibirlo hasta rayar en la ridiculez. Los «generosos» de Valencia pertenecían a la pequeña nobleza, y su título correspondía aproximadamente a la condición de los hidalgos castellanos.
} 
virtud del cual los hombres de letras están precisamente tratando de conquistar su independencia intelectual mediante las nuevas formas de creación, difusión y gestión cultural ${ }^{26}$. Por lo demás, y finalmente, debe notarse que si bien don Gregorio estuvo condicionado desde un primer momento por el pasado austracista de su familia, en ocasiones resulta sorprendente su falta de sentido político, como puede advertirse, por ejemplo, a propósito de su relación con el embajador inglés Benjamín Keene.

Los Iriarte estaban mejor situados y orientados políticamente que Mayans. Fieles a la nueva monarquía desde un primer momento, gracias a la ayuda del Duque de Béjar lograron entrar en la secretaría de Estado. Vinculados a la secretaría, a la Real Biblioteca y a las Reales Academias, cuando Carlos III subió al trono estaban en mejor posición que Mayans, que además sufriría la oposición de Pérez Bayer.

$\mathrm{Y}$ en efecto, el reinado de Carlos III inaugura un nuevo período caracterizado por un reformismo más decidido. Es entonces cuando cambia la suerte de Mayans, que goza del favor de Roda y Aranda, y con cuya intercesión logrará don Gregorio el anhelado reconocimiento. Mayans debió advertir los cambios que se estaban produciendo, y en este contexto, y ante las posibilidades y oportunidades que prometía la nueva coyuntura y que favorecía su nueva y mejorada posición, intentó un acercamiento a los bibliotecarios reales, que aparentemente correspondieron a los buenos propósitos de don Gregorio. En este momento el absolutismo borbónico quiere legitimarse sirviéndose del reformismo ilustrado, y oficialmente no están bien vistas las polémicas, que al poner en cuestión su discurso de progreso y prosperidad pueden dañar también el prestigio de la Monarquía. El propio Martínez Pingarrón hace referencia a este cambio en una carta a Mayans del 7 de noviembre de 1769 (Mayans y Siscar 1989, pp.225-227). Cuenta Pingarrón que Santander había pedido a Iriarte que eliminara de su Biblioteca griega las críticas a Pérez Bayer, pues «ya son otros los tiempos y las circunstancias». No obstante, el asunto de las correcciones a la Bibliotheca de Casiri, las críticas de Iriarte en su Biblioteca griega y, finalmente, la pugna por las gramáticas latinas volverían a enturbiar las relaciones entre don Gregorio y los bibliotecarios.

\section{CONCLUSIONES PARA LA HISTORIOGRAFÍA DE LA GRAMÁTICA LATINA DEL SIGLO XVIII EN ESPAÑA}

Javier Espino (2010) ha estudiado las diferentes tendencias que pueden advertirse en la evolución de la gramática latina en Francia y España desde finales del siglo XVI. Señala que en España los jesuitas tuvieron el control de la educación preuniversitaria hasta su expulsión en 1767. El predominio de la Compañía en la enseñanza del latín tuvo como consecuencia el paulatino abandono de las tendencias humanistas y «racionalistas» que representaba la Minerva del Brocense en beneficio de una nueva orientación de influjo barroco cuyas principales características eran la «hispa-

\footnotetext{
26 Álvarez Barrientos (1994, p. 16) ha señalado que Tomás de Iriarte «tenía fuerte conciencia de la profesionalidad de la actividad literaria».
} 
nización» y la «barroquización». Consistía lo primero en la contaminación de las reglas gramaticales del latín por el sistema lingüístico del castellano; lo segundo, en un distanciamiento de los textos clásicos y un progresivo recargamiento de los preceptos gramaticales. Espino (2010, p.275) añade que «el carácter propedéutico de la institución ignaciana, profundamente influido por la estética barroca del Siglo de Oro español, sustituyó el método interpretativo por uno memorístico y formal, basado únicamente en la acumulación». Esta tendencia, que seguía el modelo de la gramática normativa del XVI pero desvirtuado por la profusión de reglas y excepciones, se mantuvo hasta la primera mitad del siglo XVIII.

Espino afirma que esta situación empezó a cambiar a mediados del siglo XVIII por el influjo de las ideas gramaticales de Port-Royal. Distingue tres orientaciones. A mediados de la centuria, coexisten las gramáticas del método barroco-jesuítico en las que ya se advierte cierto influjo indirecto del racionalismo, como la de Pastor Ábalos y Mendoza, con otras de orientación más empirista, como las de Alfonso García de Rabadán y Antonio de la Cruz del Prado, que concitaron una fuerte oposición. Las tendencias anteriores coexisten durante la segunda mitad de la centuria con la de los eclécticos, representados por los jesuitas reformistas y los humanistas valencianos. Espino sitúa la gramática de Mayans precisamente en este grupo, que no se habría dejado influir por el racionalismo francés, sino por el «racionalismo humanista» de los autores españoles del siglo XVI, como el Brocense o Simón Abril. Finalmente, la expulsión de los jesuitas en 1767 y del decreto de Carlos III de 1768, por el que se establecía la enseñanza del latín en español, favorecieron la aparición de un gran número de gramáticas de «cuño port-royalista», y en esta tendencia sitúa la gramática de Iriarte. No obstante, reconoce que a menudo aquel influjo era indirecto o superficial, y se concretaba en la redacción de manuales más sencillos y con menos reglas. Por lo demás, las gramáticas de influencia empirista no tuvieron mucha difusión hasta el siglo XIX. No obstante, concluye Espino (2010, p.282), «el triunfo final en España del portroyalismo, aunque moderado, acabó por eliminar prácticamente de la gramática la enseñanza artificiosa del método barroquizante jesuítico».

Independientemente de la estimable aportación de Javier Espino, nuestra interpretación de la pugna entre dos de las gramáticas más importantes de la época revela que es necesario prestar atención a los hechos concretos tal y como podemos reconstruirlos a partir de los datos disponibles, pues son muchos los factores que deben tenerse en cuenta además de las cuestiones epistemológicas e ideológicas, sobre las cuales quisiéramos hacer algunas matizaciones finales.

En efecto, nuestro examen del enfrentamiento de Mayans y los Iriarte nos muestra que es necesaria la perspectiva externa para interpretar adecuadamente la historia de la gramática latina en España durante el siglo XVIII. En realidad, la perspectiva interna es insuficiente para explicar la historia de las ideas lingüísticas en las etapas anteriores a la lingüística moderna. En este sentido, y tras comparar la gramática empirista de John Wilkins (An essay towards a real character and a philosophical Languaje, 1968) con la racionalista de Lancelot y Arnauld (Grammaire générale et raisonnée, 1960), Xavier Laborda Gil (1981) ha señalado que la dicotomía empirismo-racionalismo es insuficiente para caracterizar ambas obras, pues hay elementos de las dos 
tendencias en ambas, y en ambas se combinan con otro no menos importante: la tradición. Nuestras investigaciones sobre el siglo XVIII (Perdomo Batista 2011a y 2011b) confirman la opinión de Laborda.

En el caso concreto que nos ocupa, es necesario precisar, en primer lugar, que la influencia del racionalismo en la gramática latina puede tener dos orientaciones. Una se refiere a una racionalización de la enseñanza según ciertos criterios de racionalidad y utilidad más o menos extendidos en la época; la otra se refiere específicamente al influjo del racionalismo y el empirismo en la teoría gramatical. Así pues, debemos distinguir cuidadosamente los efectos del pensamiento racionalista en la teoría pedagógica y en la teoría gramatical. El propio Espino (2011, p. 280) parece advertir esta circunstancia cuando afirma que el influjo del racionalismo en las gramáticas «port-royalistas» a menudo era indirecto y superficial, y que se concretaba en una búsqueda de manuales más sencillos y menos densos. Debemos señalar que, en la práctica, lo que distinguía ciertas gramáticas de tendencia «por-royalista» de aquellos otros primeros manuales jesuíticos en los que ya se advierte el influjo racionalista era la racionalización pedagógica de las primeras. Así pues, podría decirse que, en general, tenemos un grupo de gramáticas de corte racionalista con diferente grado de innovación teórica que se distinguían por la aplicación de un criterio de racionalización didáctica, criterio del que, por cierto, tal vez no deban excluirse las gramáticas eclécticas de los humanistas. En cuanto al eclecticismo de Mayans, Antonio Mestre (Gregorio Mayans, 2002) ha señalado que si bien su metafísica todavía se inspira en gran medida en la tradición aristotélica, en física fue básicamente mecanicista, y sus ideas estaban en consonancia con la nueva filosofía natural (cartesianismo, atomismo). Señala también que en la Razonatoria de don Gregorio puede advertirse la influencia de Locke, aunque frecuentemente emplea una terminología escolástica. Finalmente, y por lo que respecta a la obra de Iriarte, situada por Espino en la tendencia «port-royalista», María-Elisa Cuyás de Torres (1996a) ha señalado el eclecticismo de don Juan en su enfoque de las figuras retóricas.

La aplicación de conceptos y nociones procedentes de la filosofía y de la historia de las ideas tiene un indudable valor heurístico para la historiografía de la lingüística, pero de ningún modo puede remplazar la búsqueda de otras hipótesis explicativas, pues de lo contrario se estará haciendo filosofía del lenguaje o «historia intelectual», pero no precisamente historia de la lingüística. Uno de los ejemplos más claros en este sentido es el intento de explicar la lingüística dieciochesca española mediante la adscripción de autores, obras e ideas a las distintas corrientes de pensamiento de la época (empirismo, racionalismo, etc.). En puridad, la mera reconstrucción racional de carácter «presentista», que es uno de los «riesgos» de la historiografía de la lingüística, no constituye un discurso histórico. Sobre la necesidad y las posibilidades de una historiografía de la lingüística de carácter «contextualista» y hermenéutico pueden verse, por ejemplo, Perdomo-Batista (2012) y Laborda Gil (2002 y 2010).

En cuanto a los aspectos ideológicos, debemos señalar que al menos resulta cuestionable la siguiente afirmación de Espino (2010, p. 281): «Gracias a que los ilustrados vieron el jansenismo port-royalista como promotor de su lucha filosófica, política y religiosa contra el Estado absoluto y contra la Compañía de Jesús, fue posible 
que se admitiera su pedagogía gramatical como legítima y acorde a las nuevas reformas que pretendía la Ilustración: formar ciudadanos útiles para un nuevo Estado en el que el monarca pasa a ser un enviado de Dios con poderes absolutos a ser un padre que cuida por el bienestar de sus hijos-súbditos [...]». En realidad, y salvo que se quiera identificar la Ilustración con la Revolución, el movimiento ilustrado no pretendía socavar las bases del Antiguo Régimen, y a veces se ha señalado su carácter esencialmente moderado. En el caso de España, la oposición a la Compañía de Jesús, que representaba el centralismo romano, y cuya expulsión por cierto aún no ha sido suficientemente explicada, a menudo tenía el propósito de fortalecer las regalías de la corona y, en definitiva, el poder absoluto del monarca. Finalmente, tal vez fuera más prudente afirmar que a finales de la centuria empieza advertirse la transformación del monarca en el depositario de la soberanía de pueblo. Una perspectiva hermenéutica y contextualista quizá pudiera preservarnos de los riesgos que comportan este tipo de interpretaciones. Por lo demás, y finalmente, quisiéramos señalar que esta clase de enfoque tal vez pueda iluminarnos sobre los condicionantes actuales de las decisiones de la política educativa que afectan a la enseñanza de la cultura clásica y de las humanidades en general y sobre las consecuencias de tales decisiones, y quizá esta sea una de las principales aportaciones de la historiografía de la lingüística.

\section{REFERENCIAS BIBLIOGRÁFICAS}

Aguilar Piñal, F. (1991), Introducción al siglo XVIII, Madrid, Ediciones Júcar.

AlbiñAnA, S. (1981), «Los conflictos escolásticos y el rectorado de Juan Antonio Mayans en la Universidad de Valencia», en Mayans y la Ilustración: Simposio Internacional en el bicentenario de la muerte de Gregorio Mayans (Valencia-Oliva, 30 de sept. - 2 oct.), II,Valencia, Ayuntamiento de Oliva, pp. 411-428 [en línea]. Gregorio Mayans digital. Biblioteca Valenciana Digital. <http://bivaldi.gva.es/estaticos/contenido.cmd?pagi na=estaticos/mayans/mayans_inicio $>$. [Consulta 14 de julio de 2011].

Alemany Peiró, A. (1994), Juan Antonio Mayans y Siscar (1718-1801): Esplendor y crisis de la Ilustración valenciana, Valencia, Ayuntamiento de Oliva [en línea]. Gregorio Mayans digital. Biblioteca Valenciana Digital. <http://bivaldi.gva.es/estaticos/contenido.cmd?pagi na=estaticos/mayans/mayans_inicio $>$. [Consulta 14 de julio de 2011].

Álvarez Barrientos, J. (1994), «El escritor según Tomás de Iriarte: su plan de una Academia de Ciencias y Buenas Letras», en Anales de Literatura Española 10, 9-36.

Álvarez Barrientos, J. (1999), «Gregorio Mayans (1699-1781), hombre de letras», en Mestre Sanchis, A. (coord.), Actas del Congreso Internacional sobre Gregorio Mayans (Valencia-Oliva, 6 al 8 de mayo de 1999), Oliva, Ayuntamiento de Oliva, pp. 239-249 [en línea]. Gregorio Mayans digital. Biblioteca Valenciana Digital, $<\mathrm{http}$ ///bivaldi.gva.es/esta ticos/contenido.cmd?pagina=estaticos/mayans/mayans_inicio $>$. [Consulta 14 de julio de 2011].

Álvarez Barrientos, J. (2006), Los hombres de letras en la España del siglo XVIII. Apóstoles y arribistas, Madrid, Editorial Castalia.

Bartolomé Martínez, B. (1984), «La Academia Latina Matritense y el intrusismo en las aulas de latinidad en el siglo XVIII (1755-1800)», en Educación e Ilustración en España, III Coloquio de Historia de la Educación, Barcelona, Universidad de Barcelona, pp. 382-393. 
BordAZAR DE ARTAZÚ, A. (1728), Ortografía española fijamente ajustada a la naturaleza invariable de cada una de las letras, Valencia: imprenta del autor.

CRuZAdo, J. (1945), «La polémica Mayans-Diario de los Literatos. Algunas ideas gramaticales y una cuestión estética», en Boletín de la Biblioteca de Menéndez Pelayo XXI, 2, 133-151.

CuyÁs DE Torres, M.-E. (1992), «La gramática latina de Juan de Iriarte», ExcPhilol 2, pp. 133-148.

CuYÁs DE Torres, M.-E. (1996a), «Estudio de las figuras en la Gramática de Juan de Iriarte», Myrtia: Revista de filología clásica 11, pp. 33-46.

CuYÁs DE TORRES, M.-E. (1996b), «Una cuestión de sintaxis: ¿Qué pensaba Juan de Iriarte del Ablativo Absoluto?», $C F C(L)$ 10, 237-253.

CuyÁs de TorRes, M.-E. (2002), «Casos y preposiciones en Juan de Iriarte», en SANTANA HenríQueZ, G. y SANTANa SANJurJo, V. (eds.), Studia humanitatis in honorem Antonio Cabrera Perera, Las Palmas de Gran Canaria, Universidad de Las Palmas de Gran Canaria, pp. 427-437.

CuYÁs DE TorRes, M.-E. (2005a), «Juan de Iriarte versus Nebrija. A propósito del participio pasivo castellano en locuciones con valor temporal», $C F C(L)$ 25.2, 123-140.

CuYÁs DE TORRES, M.-E. (2005b), «El participio pasivo castellano en Juan de Iriarte: Una aproximación», en Santana HenríQuez, G., QueVedo García, F.J. y SANTANA Martel, E. (coords.), Con quien tanto quería: Estudios en homenaje a María del Prado Escobar Bonilla, Las Palmas de Gran Canaria, Universidad de Las Palmas de Gran Canaria, pp. 121-126.

Diario de los Literatos de España (1987 [1737-1742]), Diario de los Literatos de España, edición facsímil con estudio introductorio de Jesús M. Ruiz Veintemilla, 7 vols., Barcelona, Puvill-Libros. También se puede consultar en las ediciones digitales de la Biblioteca Virtual Miguel de Cervantes ( $<$ http://www.cervantesvirtual.com $>$ ) y del Programa de búsqueda de libros de Google (<http://books.google.com/ $>$ ).

EsPino Martín, J. (2001), «Un enfoque de las gramáticas latinas en el panorama cultural de la ilustración española», en Crespo, E. y BARrios CASTro, Mª.J. (eds.), Actas del X Congreso Español de Estudios Clásicos (21-25 de septiembre de 2009), III, Madrid, Sociedad Española de Estudios Clásicos, pp. 545-551.

EsPino MARTín, J. (2002), «La gramática latina como trasfondo educativo de las luchas ideológicas de jesuitas, escolapios e ilustrados durante el siglo XVIII español», en Iglesia y religiosidad en España: historia y archivos, Actas de las V Jornadas de Castilla-La Mancha sobre investigación en archivos (Guadalajara, 8-11 de mayo de 2001), II, pp. 1075-1081.

ESPINO MARTín, J. (2003a), «Racionalismo e Ilustración en la enseñanza del latín: evolución de las gramáticas escolapias en la segunda mitad del siglo XVIII», $C F C$ (L) 23.2, 423-435 [en línea] Dialnet, Servicio de Alertas Informativas y de Acceso a los Contenidos de la Literatura Científica Hispana. Universidad de La Rioja. <http://dialnet.unirioja.es/>. [Consulta: 2 de diciembre de 2011].

EsPino MARTín, J. (2003b), «Política y enseñanza del latín: liberales y conservadores en la gramática latina durante el reinado de Fernando VII», en Estudios Clásicos, t. 45, n. ${ }^{\circ}$ 123, 2003, 45-65 [en línea]. Dialnet, Servicio de Alertas Informativas y de Acceso a los Contenidos de la Literatura Científica Hispana. Universidad de La Rioja. < http://dialnet. unirioja.es/>. [Consulta: 2 de diciembre de 2011].

ESPINO MARTín, J. (2006), Evolución de la enseñanza gramatical jesuítica en el contexto sociocultural español entre los siglos XVI y primera mitad del XVIII, Universidad Complutense de Madrid, Servicio de Publicaciones [en línea]. Biblioteca Digital Complutense. $<$ http://cisne.sim.ucm.es/>. [Consulta: 3 de diciembre de 2011]. 
ESPINO MARTín, J. (2007), «Evolución de la enseñanza gramatical en la América Hispana durante el siglo XVIII: el Virreinato del Río de la Plata y la enseñanza jesuítica de la lengua latina», en Bibliographica Americana 4, 1-17 [en línea]. Bibliographica Americana, Revista Interdisciplinaria de Estudios Coloniales. < http://200.69.147.117/revistavirtual//>. [Consulta: 4 de diciembre de 2011].

ESPINO MARTín, J. (2008), «Panorama de la enseñanza gramatical de los Jesuitas españoles hasta su expulsión», en Maestre Maestre, J.M., Pascual Barea, J. y Charlo Brea, L. (eds.), Humanismo y pervivencia del mundo clásico: homenaje al profesor Antonio Prieto IV.2, Madrid, CSIC, (Las artes literarias en el Renacimiento), pp.807-820.

Espino Martín, J. (2010), «Enseñanza del latín e historia de las ideas: la revolución de Port Royal y su repercusión en Francia y España durante el siglo XVIII», Minerva: Revista de filología clásica 23, 261-284.

Estellés i GonZÁlez, J. M. a (1999), «El magisterio de M. Martí. Aportaciones de la edición alemana de los Epistolarum libri VI de Mayans», en Mestre SAnchis, A. (coord.), Actas del Congreso Internacional sobre Gregorio Mayans (Valencia-Oliva, 6 al 8 de mayo de 1999), Oliva, Ayuntamiento de Oliva, pp. 197-214 [en línea]. Gregorio Mayans digital. Biblioteca Valenciana Digital, <http://bivaldi.gva.es/estaticos/contenido.cmd?pagina =estaticos/mayans/mayans_inicio $>$. [Consulta 14 de julio de 2011].

GIL FERNÁNDEZ, L. (1997), Panorama social del humanismo español (1500-1800), Madrid, Tecnos.

HERNANDO, C. (1975), Helenismo e Ilustración (el griego en el siglo XVIII español), Madrid, Fundación Universitaria Española.

Huerta y Vega, Francisco JaVier Manuel de la (1738), España primitiva: historia de sus reyes y monarcas desde su población hasta Cristo [...], Madrid, (s. n.), Tomo Primero.

IRIARTE y CiSNeros, J. DE (1771), Gramática latina escrita con nuevo método y nuevas observaciones, en verso castellano con su explicación en prosa, Madrid, en la Imprenta de Pedro Marín. Puede consultarse la edición digital alojada en la web de la Biblioteca Virtual Miguel de Cervantes (<http://www.cervantesvirtual.com/ $>$ ).

IRIARTE Y CiSNEROS, J. DE (1774), Obras sueltas de Juan de Iriarte publicadas en obsequio de la literatura a expensas de varios caballeros amantes del ingenio y del mérito, 2 vols., Madrid, en la Imprenta de D. Francisco Manuel de Mena. Puede consultarse la edición digital del Programa de búsqueda de libros de Google (<http://books.google.com/ $>$ ).

IRIARTE y Nieves-RaVelo, T. DE (1805), Colección de obras en verso y prosa de D. Tomás de Iriarte, 8 vols., Madrid, Imprenta Real. Pueden consultarse las ediciones digitales de la Biblioteca Virtual Miguel de Cervantes (<http://www.cervantesvirtual.com $>$ ) y el Programa de búsqueda de libros de Google ( $<$ http://books.google.com $/>$ ).

Laborda GiL, X. (1981), Racionalismo y empirismo en la lingüística del siglo XVII. PortRoyal y John Wilkins. Tesis doctoral dirigida por Jesús Tusón Vals. Barcelona [en línea]. Departamento de Lingüística General, Universidad de Barcelona. <http://www.tdr.cesca. es/TDX-0920104-113747/>. [Consulta: 19 de octubre de 2011].

LABORDA GIL, X. (2002): «Historiografía Lingüística: veinte principios del programa de la investigación hermenéutica», Revista de investigación lingüistica 5.1, 2002, pp. 179-208.

LABORDA GIL, X. (2011): «La Lingüística y el historiador perfecto», Círculo de lingüística aplicada a la comunicación 46, pp. 51-90.

LiNCH, J. (2007), El siglo de las reformas: la Ilustración, en LYNCH, J. (dir.), Historia de España, n. ${ }^{\circ}$ 16, Madrid, El País.

LóPEz, F. (1999), Juan Pablo Forner (1756-1797) y la crisis de la conciencia española, Valladolid, Junta de Castilla y León. 
MAYANS y Siscar, G. (1732), Gregorii Maiansii, generosi et antecessoris Valentini, Epistolarum libri sex, Valentiae Edetanorum, typis Ant. Bordazar de Artazú.

Mayans y Siscar, G. (1734), Pensamientos literarios que propuso don Gregorio Mayans y Siscar [...] con ocasión de dedicar a su excelencia el libro intitulado Cartas morales, militares, civiles y literarias de varios autores españoles, Madrid, Juan de Zúñiga.

Mayans y Siscar, G. (1737a), Vida de Miguel de Cervantes, Briga Real, (s. i.) [en línea]. Gregorio Mayans y Siscar digital. Biblioteca Valenciana Digital. $<$ http://bivaldi.gva.es/estati cos/contenido.cmd?pagina=estaticos/mayans/mayans_inicio $>$. [Consulta 14 de julio de 2011]. Puede consultarse también la edición del programa de búsqueda de libros de Google $(<$ http://books.google.com/ $>)$.

MAYANS y SiSCAR, G. (1737b), Orígenes de la lengua española compuestos por varios autores, recogidos por don Gregorio Mayans y Siscar [...]. 2 vols., Madrid, Juan de Zúñiga. [Edición facsímil, Madrid, Atlas, 1981]. También pueden consultarse las ediciones digitales del programa de búsqueda de libros de Google (<http://books.google.com/ $>$ ) y la Biblioteca Valenciana Digital ( $<$ http://bivaldi.gva.es/estaticos/contenido.cmd?pagina $=$ estati cos/mayans/mayans_inicio $>$ ).

MAYANS y SiscaR, G. (1737c), Conversación sobre el Diario de los Literatos de España. La publicó don Plácido Veranio, Madrid, Juan de Zúñiga.

MAYANS y SisCAR, G. (1774), Organum rhetoricum et oratorium: concinnatum ex Arte Rhetorica Aelii Antonii Nebrissensis, cum notis Gregorii Maiansii [...]. Et ex Institutionibus Oratoriis Petri Joannis Nunnesii, cum eiusdem auctoris annotationibus [...], Tabulae rhetoricae, Valentiae Edetanorum, apud Franciscum Burguete, 1774

Mayans y Siscar, G. (1972), Epistolario, II. Mayans y Burriel, Valencia, Diputación [en línea]. Gregorio Mayans digital. Biblioteca Valenciana Digital. $<$ http://bivaldi.gva.es/esta ticos/contenido.cmd?pagina=estaticos/mayans/mayans_inicio $>$. [Consulta 14 de julio de 2011].

MAYANS y Siscar, G. (1973), Epistolario III. Mayans y Martí, Valencia, Diputación [en línea]. Gregorio Mayans digital. Biblioteca Valenciana Digital. <http://bivaldi.gva.es/estaticos/ contenido.cmd?pagina=estaticos/mayans/mayans_inicio $>$. [Consulta 14 de julio de 2011].

Mayans y Siscar, G. (1987), Epistolario, VII. Mayans y Martínez Pingarrón, 1: Historia cultural de la Real Biblioteca, Valencia, Diputación [en línea]. Gregorio Mayans digital. Biblioteca Valenciana Digital. <http://bivaldi.gva.es/estaticos/contenido.cmd?pagina=estati cos/mayans/mayans_inicio $>$. [Consulta 14 de julio de 2011].

MAYANS y SisCAR, G. (1988), Epistolario, VIII. Mayans y Martinez Pingarrón, 2: Los manteistas y la cultura ilustrada, Valencia, Diputación [en línea]. Gregorio Mayans digital. Biblioteca Valenciana Digital. <http://bivaldi.gva.es/estaticos/contenido.cmd?pagina=estati cos/mayans/mayans_inicio $>$. [Consulta 14 de julio de 2011].

Mayans y Siscar, G. (1989), Epistolario, IX. Mayans y Martínez Pingarrón, 3: Real Biblioteca y politica cultural, Valencia, Diputación [en línea]. Gregorio Mayans digital. Biblioteca Valenciana Digital. <http://bivaldi.gva.es/estaticos/contenido.cmd?pagina=estati cos/mayans/mayans_inicio $>$. [Consulta 14 de julio de 2011].

Mayans y Siscar, G. (1990), Epistolario, X. Mayans con Manuel Roda y el Conde de Aran$d a$, Valencia, Diputación [en línea]. Gregorio Mayans digital. Biblioteca Valenciana Digital. $<$ http://bivaldi.gva.es/estaticos/contenido.cmd?pagina=estaticos/mayans/mayans inicio $>$. [Consulta 14 de julio de 2011].

MAYANS y SiscaR, G. (1993), Epistolario, XII. Mayans y los libreros, Valencia, Diputación [en línea]. Gregorio Mayans digital. Biblioteca Valenciana Digital. $<$ http://bivaldi.gva.es/estati cos/contenido.cmd?pagina=estaticos/mayans/mayans_inicio $>$. [Consulta 14 de julio de 2011]. 
MaYAns y SiscaR, G. (1997), Epistolario, XV. Mayan y los altos cuadros de la magistratura y administración borbónica, 2 (1751-1781), Valencia, Diputación [en línea]. Gregorio Mayans digital. Biblioteca Valenciana Digital. <http://bivaldi.gva.es/estaticos/contenido. cmd?pagina=estaticos/mayans/mayans_inicio $>$. [Consulta 14 de julio de 2011].

MAYANS y Siscar, G. (1998), Epistolario, XVI. Mayans y los altos cuadros de la magistratura y la administración borbónica, 3. Fernando José de Velasco Ceballos (1753-1781),Valencia, Diputación [en línea]. Gregorio Mayans digital. Biblioteca Valenciana Digital. $<$ http://bivaldi.gva.es/estaticos/contenido.cmd?pagina=estaticos/mayans/mayans_inicio $>$. [Consulta 14 de julio de 2011].

Mayans y Siscar, G. (2000), Epistolario, XVII. Cartas literarias. Correspondencia de los hermanos Mayans con los hermanos Andrés, F. Cerdá y Rico, Juan Bta. Muñoz y José Vega Sentmenat, Valencia, Diputación [en línea]. Gregorio Mayans digital. Biblioteca Valenciana Digital. $<$ http://bivaldi.gva.es/estaticos/contenido.cmd?pagina=estaticos/mayans/ma yans_inicio>. [Consulta 14 de julio de 2011].

Mayans y Siscar, G. (2002), Gregorio Mayans y Siscar digital. Obras completas. Epistolario. Bibliografía, edición en un cederrón, Biblioteca Virtual Menéndez Pelayo de Polígrafos Españoles 2, Polígrafos Valencianos 1, Fundación Hernando de Larramendi y Biblioteca Valenciana. Esta edición es accesible en Internet a través de la página web de la Biblioteca Valenciana Digital ( $<$ http://bivaldi.gva.es/estaticos/contenido.cmd?pagina=estati cos/mayans/mayans_inicio $>)$.

Martínez Alcalde, M. ${ }^{a}$ J. (1992), Las ideas lingüisticas de Gregorio Mayans, Valencia, Universidad de Valencia [en línea]. Gregorio Mayans digital. Biblioteca Valenciana Digital. $<$ http://bivaldi.gva.es/estaticos/contenido.cmd?pagina=estaticos/mayans/mayans_inicio $>$. [Consulta 14 de julio de 2011].

Mestre Sanchis, A. (1970), Historia, fueros y actitudes politicas: Mayans y la historiografía del siglo XVIII, Valencia, (s. n.) [en línea]. Gregorio Mayans digital. Biblioteca Valenciana Digital. $<$ http://bivaldi.gva.es/estaticos/contenido.cmd?pagina=estaticos/mayans/ mayans_inicio $>$. [Consulta 14 de julio de 2011].

Mestre Sanchis, A. (1978), El mundo intelectual de Mayans, Oliva, Ayuntamiento [en línea]. Biblioteca Valenciana Digital. $<$ http://bivaldi.gva.es/estaticos/contenido.cmd?pagina=estati cos/mayans/mayans_inicio $>$. [Consulta 14 de julio de 2011].

Mestre Sanchis, A. (1981), Perfil biográfico de don Gregorio Mayans y Siscar, Valencia, Ayuntamiento de Oliva [en línea]. Gregorio Mayans digital. Biblioteca Valenciana Digital. $<$ http://bivaldi.gva.es/estaticos/contenido.cmd?pagina=estaticos/mayans/mayans_inicio $>$. [Consulta 14 de julio de 2011].

Mestre SAnchis, A. (1985), «Relación epistolar-cultural entre el editor lionés Roque Deville y Mayans», en Revista de historia moderna: Anales de la Universidad de Alicante 5, 141-155.

Mestre Sanchis, A. (1999), Don Gregorio Mayans y Siscar, entre la erudición y la política, Valencia, Institució Alfons el Magnànim, Diputación de Valencia [en línea]. Gregorio Mayans digital. Biblioteca Valenciana Digital. <http://bivaldi.gva.es/estaticos/contenido. cmd?pagina=estaticos/mayans/mayans_inicio $>$. [Consulta 14 de julio de 2011].

Mestre Sanchis, A. (2000), «Monarca, instituciones e individuos en los orígenes de la Ilustración», en Cuadernos Dieciochistas 1, 19-37.

Molas Ribalta, P. (1981), «Mayans descrito por él mismo. Un memorial inédito de 1766», en Mayans y la Ilustración: Simposio Internacional en el bicentenario de la muerte de Gregorio Mayans (Valencia-Oliva, 30 de sept. - 2 oct.), I,Valencia, Ayuntamiento de Oliva, pp. 123-129 [en línea]. Gregorio Mayans digital. Biblioteca Valenciana Digital. <http:// 
bivaldi.gva.es/estaticos/contenido.cmd?pagina=estaticos/mayans/mayans_inicio $>$. [Consulta 14 de julio de 2011].

OchoA, E. (1870), Epistolario español. Colección de cartas de españoles ilustres antiguos y modernos, vol. II., en Biblioteca de Autores Españoles, LXII, Madrid, M. Rivadeneyra [en línea]. Edición en facsímil digital realizada a partir de la anterior por el programa de búsqueda de libros de Google. Google. $<$ http://books.google.com/>. [Consulta 14 de julio de 2011].

Perdomo-Batista, M. A. (2011a), Filología e Ilustración en España: el discurso sobre la decadencia en las letras españolas del siglo XVIII. Tesis doctoral inédita dirigida por Antonio Manzanares Pascual y presentada en la Universidad de Las Palmas de Gran Canaria el 19 de septiembre de 2011. Depósito de Tesis de la Biblioteca General de la ULPGC, Campus de Tafira.

Perdomo-Batista, M. A. (2011b), «La ascensión de los Iriarte. A propósito de la relación entre políticos y literatos en la España del absolutismo borbónico», en Philológica Canariensia $16-17$, (en prensa).

Perdomo-Batista, M. A. (2011c), «Sobre el concepto de Ilustración periférica: el estatuto de lo local en el pensamiento ilustrado español. El ejemplo de Viera y Clavijo», en Anuario de Estudios Atlánticos 58 (en prensa).

Perdomo-Batista, M. A. (2012), «Propuestas para una historiografía de la lingüística de base hermenéutica», en Revista de Filología de la Universidad de La Laguna (en prensa).

Salas SAlgado, F. (2005), «Un episodio sobre la enseñanza del latín en el siglo XVIII en Los literatos en Cuaresma de Tomás de Iriarte», separata de El Museo Canario, LX, pp. 261-277.

SANTOs Puerto, J. (1999), «La censura de la España primitiva: una aclaración historiográfica», Hispania, vol. LIX/2, n. ${ }^{\circ} 202,547-564$.

SAlustio Crisipo, C. (1772), La conjuración de Catalina y la Guerra de Jugurta, traducción de D. Gabriel de Borbón, Infante de España, revisión de Francisco Pérez Bayer, Madrid, Joaquín Ibarra.

Siles, J. (1999), «Mayans o el fracaso de la inteligencia», en Mestre SAnchis, A. (coord.), Actas del Congreso Internacional sobre Gregorio Mayans (Valencia-Oliva, del 6 al 8 de mayo 1999), Oliva, Ayuntamiento de Oliva, pp. 665-686 [en línea]. Gregorio Mayans digital. Biblioteca Valenciana Digital. $<$ http://bivaldi.gva.es/estaticos/contenido.cmd?pagina=es taticos/mayans/mayans_inicio $>$. [Consulta 14 de julio de 2011].

Tubau, X. (2004), «El Arte que Nebrija no compuso: sobre Juan de Iriarte y su Gramática latina», Península. Revista de Estudios Ibéricos 1, 423-435. 